\title{
Quantum chemical computations, fluorescence spectral features and molecular docking of two biologically active heterocyclic class of compounds
}

\author{
Raveendra Melavanki $^{\text {a,b, }, 1}$, Kalpana Sharma ${ }^{a}$, V.T. Muttannavar ${ }^{c}$, Raviraj Kusanur ${ }^{\text {d, } 1}$, \\ Kariyappa Katagi ${ }^{\mathrm{e}}$, Swarna M Patra ${ }^{\mathrm{d}}$, Siva Umapathy ${ }^{\mathrm{f}}$, Kishor Kumar Sadasivuni ${ }^{\mathrm{g}, * *}$, \\ Vikas M Shelar $^{\mathrm{h}}$, Diksha Singh ${ }^{\mathrm{h}}$, NR Patil ${ }^{\mathrm{i}}$, Varsha V Koppal ${ }^{\mathrm{i}}$ \\ ${ }^{a}$ Department of Physics, MS Ramaiah Institute of Technology, Bangalore, 560054, Karnataka, India \\ ${ }^{\mathrm{b}}$ Centre of Excellence for Imaging Technologies, MS Ramaiah Institute of Technology, Bangaluru, 560054, Karnataka, India \\ ${ }^{\mathrm{c}}$ Department of Physics, JSS Science RSH PU College, Vidyagiri, Dharwad, 580003, Karnataka, India \\ ${ }^{\mathrm{d}}$ Department of Chemistry, R.V. College of Engineering, Bangalore, Karnataka, India \\ ${ }^{\mathrm{e}}$ Department of Chemistry, Karnataka Science College, Dharwad, 580008, India \\ ${ }^{\mathrm{f}}$ Department of Inorganic and Physical Chemistry, Indian Institute of Science, Bangalore, Karnataka, India \\ ${ }^{\mathrm{g}}$ Centre for Advanced Materials, Qatar University, Doha, Qatar \\ ${ }^{\mathrm{h}}$ Department of Physics, MS Ramaiah University of Applied Science, Bengaluru, Karnataka, 560058, India \\ ${ }^{\mathrm{i}}$ Department of Physics, B.V.B. College of Engineering \& Technology, Hubli, 580031, Karnataka, India
}

\section{A R T I C L E I N F O}

\section{Keywords:}

Solvatochromic method

Ground state and excited state dipole moments DFT

NBO

MEP

Fukui functions

Molecular docking

\begin{abstract}
A B S T R A C T
This work is an effort for determination of excited and ground state values of dipole moments and also for quantum chemical computation of two biologically active heterocyclic class of compounds namely of 3-[2-Oxo-2(2-oxo-2H-chromen-3-yl)-ethylidene]-1,3-dihydro-indol-2-one (3OCE) and 3-[2-Oxo-2-(3-oxo-3H-benzo[f]chromen-2-yl)-ethylidene]-1,3-dihydro-indol-2-one (3OBC). Redshift is displayed by both the compounds with some enhancement in polarity of solvent. The selected molecules show comparatively more polar nature in excited state than in ground state, and this is indicated by large dipole moment in the excited state. DFT calculations with B3LYP/6-311+G (d, p) basis sets using compound's quantum chemical property such as analysis of frontier molecular orbital were used for studying chemical reactivity and kinetic stability of selected compounds. MEP, NBO and Mulliken charges are further studied. The compounds exhibit great amount of energy for stabilization, which is depicted as transfer of proton showed by natural bond orbital (NBO) analysis within the selected donor-acceptor. The indices of electrophilicity and local softness of solute compounds being used is calculated with the help of Fukui function. In order to observe the biophysical properties of the compounds, molecular docking studies performed with periplasmic proteins (PDB ID: 2IPM and 2IPL).
\end{abstract}

\section{Introduction}

In biological and chemical sensors, molecular docking, there is a significant role of heterocyclic compounds like coumarin [1-3]. Medicinal chemists in past few decades, have been exploring synthetic and natural coumarin compounds for drug applications because of the interesting pharmacological properties of coumarin ring system. Coumarin compounds which were derived synthetically, namely pyrano coumarins, coumarin sulfamates and furano coumarins found applications as anti-inflammatory, antihypertensive, antibacterial, antitumor, anti-coagulant, photo chemotherapeutic, anti-HIV and antimicrobial agents. There are remarkable applications of these compounds in dye industries [3-5]. As there is a broad range of pharmaceutical and bio-chemistry applications, dipole moments comprehension has attracted large number of researchers in the recent years. The dipole moment estimation helps in studying distribution of charge, electron density,

\footnotetext{
* Corresponding author at: M.S. Ramaiah Institute of Technology, Bangalore, 560054, Karnataka, India.

$* *$ Corresponding author.

E-mail addresses: melavanki73@gmail.com (R. Melavanki), chishorecumar@gmail.com (K.K. Sadasivuni).

1 (Affiliated to Visvesvaraya Technological University, Belagavi-590018, Karnataka, India).
} 


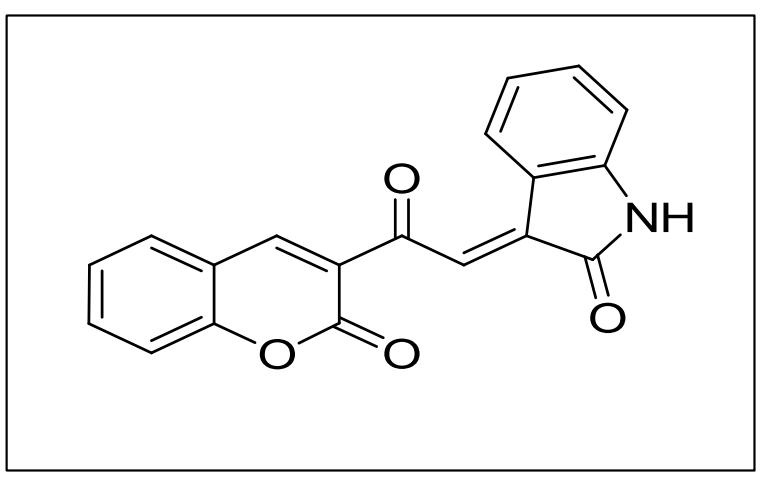

(a) $30 \mathrm{CE}$

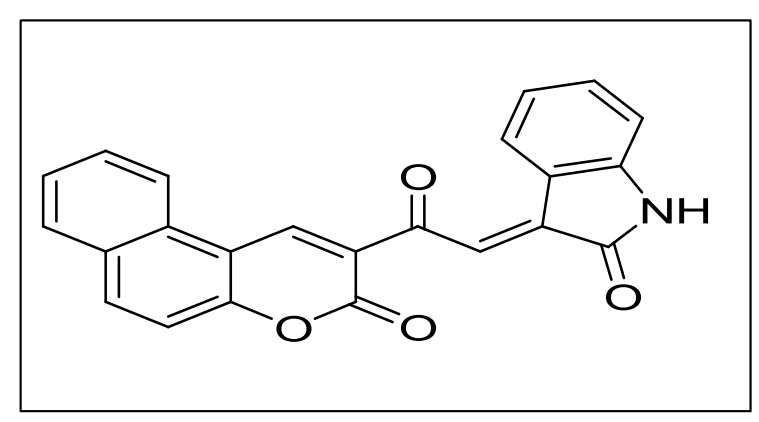

(b) $30 \mathrm{OBC}$

Fig. 1. Molecular Structures of 1(a) 3OCE and 1(b) 3OBC.

geometrical structure in short lived state of fluorophore, etc.

Dipole moment for heterocyclic compounds are determined using a widely used solvatochromic method. There is a linear correlation between absorption and emission wave number and a polarity function for the solvent. Also, correlations are found between the theories of second order perturbation and that of quantum mechanical Onsager's reaction field [6-13]. In structural discovery, coumarin compounds are found to have an extensive significance [14-31]. For the design of new pharmaceutical compounds, the information on local reactivity descriptors based on charge density and molecular reactivity is provided by density functional theory (DFT) [32-66]. The motivation for our work on the fluorescence spectral features and quantum chemical computations of coumarin compounds came from literature survey of different heterocyclic compounds. In our study, we used the solvatochromic method for calculating the excited and ground state dipole moment of compounds $30 C E$ and 3OBC. Apart from that, quantum chemical computations were carried out using Gaussian 09 program like Mulliken charges, theoretical ground state dipole moment, NBO, MEP, NLO properties and Fukai calculations. Because of the polar nature and biological activity [65] of these coumarin compounds we planned to study the biophysical properties by docking with periplasmic proteins which are the major components of blood.

\section{Materials and methods}

\subsection{Materials}

By using standard methods, we synthesized two coumarin derivatives viz, 3-[2-Oxo-2-(2-oxo-2H-chromen-3-yl)-ethylidene]-1,3dihydro-indol-2-one (3OCE) and 3-[2-Oxo-2-(3-oxo-3H-benzo[f]chromen-2-yl)-ethylidene]-1,3-dihydro-indol-2-one (3OBC) [63,65]. Solvents of different dielectric constant such as methanol (ML), acetonitrile (AN), ethanol (EL), dimethyl formamide (DMF), dimethyl sulphoxide
(DMS), tetrahydrafuran (THF) and ethyl acetate (EA) are all of spectroscopic grade. All the mentioned solvents were obtained from S-D-Fine Chemicals Ltd., India. Fig. 1(a) \& (b) shows molecular structure for compounds 3OCE and 3OBC. The molecular docking for both coumarin compounds were carried out using Auto Dock Tools version 1.5.6 software. The Best affinity mode of docked compound 3OCE and 3OBC with 2-IPM and IPL are as shown in Fig. 2(a) \& (b) and Fig. 3(a) \& 3(b)

\subsection{Spectroscopic measurements}

The fluorescence and absorption spectra of 3OCE and 3OBC are recorded in Hitachi F-2700 FL Spectroflourimeter and UV-3600 Spectrophotometer (Labomed) respectively at room temperatures. Preparation of fresh solution with concentration being $1 \times 10^{-4} \mathrm{M}$ is done in various solvents for both $3 \mathrm{OCE}$ and $3 \mathrm{OBC}$ compounds. The spectroscopic measurements are carried out with an instruments error of $\pm 1 \mathrm{~nm}$.

\section{Results and discussion}

3.1. Evaluating and investigating dipole moments for excited state and ground state through experimental approach

\subsubsection{Determining the solvent effect on emission spectra and absorption spectra}

The absorption spectra and emission spectra in 1,4 - dioxane solvent are shown in Fig. 4(a),(b) for 3OCE and Fig. 5(a),(b)for 3OBC compounds. Different spectral parameters for compounds 3OCE and 3OBC are illustrated respectively in Tables 1 and 2 . It is observed that for both compounds the magnitude Stokes shift is positive. The observation indicates a dissimilar geometry and a less polar nature in ground state as compared in excited state. Hereby $\pi \rightarrow \pi^{*}$ transition are confirmed for 3OCE and 3OBC compounds.

3.1.2. Determining dipole moment values for ground state and excited state by solvatochromic method

There are various methods to obtain the dipole moments for excited state and ground state. Those methods include solvatochromic effect, thermo chromic effect and electro chromic effect. Solvatochromic effect yields comparatively better results for wide range of compounds and so we used the same for our study. Solvatochromic shift method involves three independent equations [10-13] given as below

Lippert's equation [10],

$\left(\bar{\nu}_{a}-\bar{\nu}_{f}\right)=m_{1} F_{1}(\varepsilon, n)+$ constant

Bakhshiev's equation [11]

$\left(\bar{\nu}_{a}-\bar{\nu}_{f}\right)=m_{2} F_{2}(\varepsilon, n)+$ constant

Kawski-Chamma-Viallet'sequation [12,13]

$\frac{\left(\bar{\nu}_{a}+\bar{\nu}_{f}\right)}{2}=m_{3} F_{3}(\varepsilon, n)+$ constant

Where $F_{1}, F_{2}$ and $F_{3}$ represents parameters for solvent polarity and can be expressed as

$f_{1}(n, \varepsilon)=\left[\left(\frac{(\varepsilon-1)}{(2 \varepsilon+1)}\right)-\left(\frac{\left(n^{2}-1\right)}{\left(2 n^{2}+1\right)}\right)\right]$

$f_{2}(n, \varepsilon)=\left[\frac{\left(2 n^{2}+1\right)}{\left(n^{2}+2\right)}\right]\left[\left(\frac{\varepsilon-1}{\varepsilon+2}\right)-\left(\frac{n^{2}-1}{n^{2}+2}\right)\right]$

$f_{3}(n, \varepsilon)=\left\{\frac{1}{2} \frac{\left(2 n^{2}+1\right)}{\left(n^{2}+2\right)}\left[\frac{\varepsilon-1}{\varepsilon+2}-\frac{n^{2}-1}{n^{2}+2}\right]+\frac{3}{2}\left[\frac{n^{4}-1}{\left(n^{2}+2\right)^{2}}\right]\right\}$

where

$\bar{\nu}_{a}$-represents maxima wavenumber in absorption spectrum 


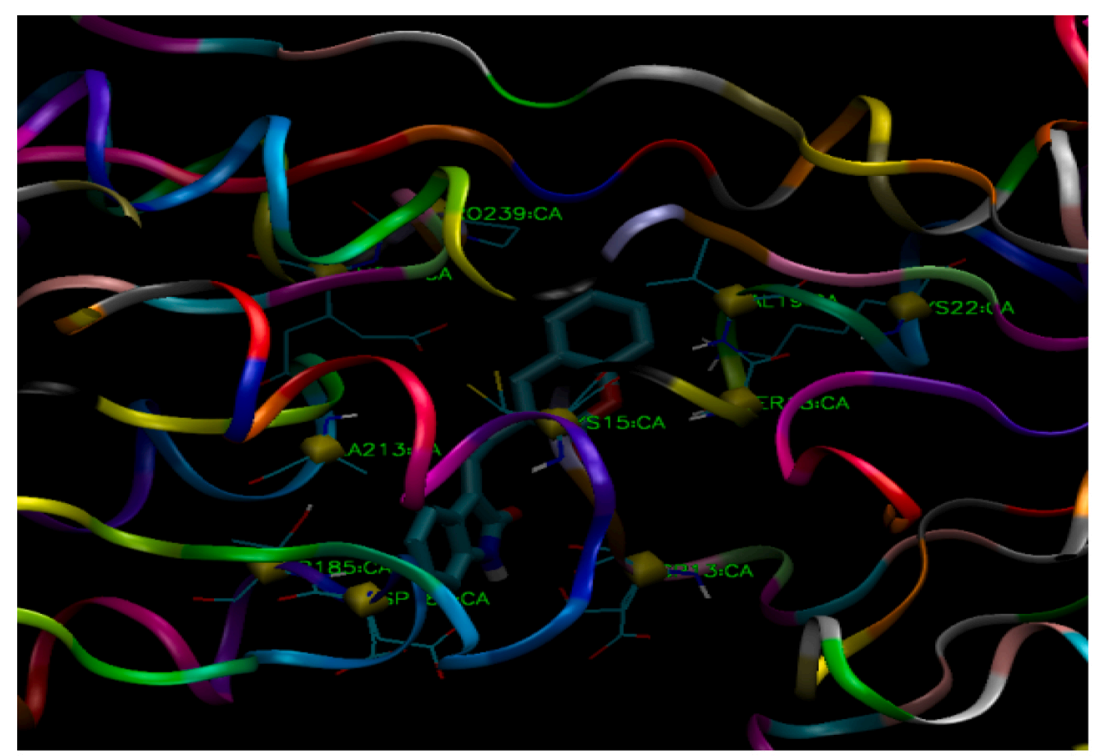

(a)

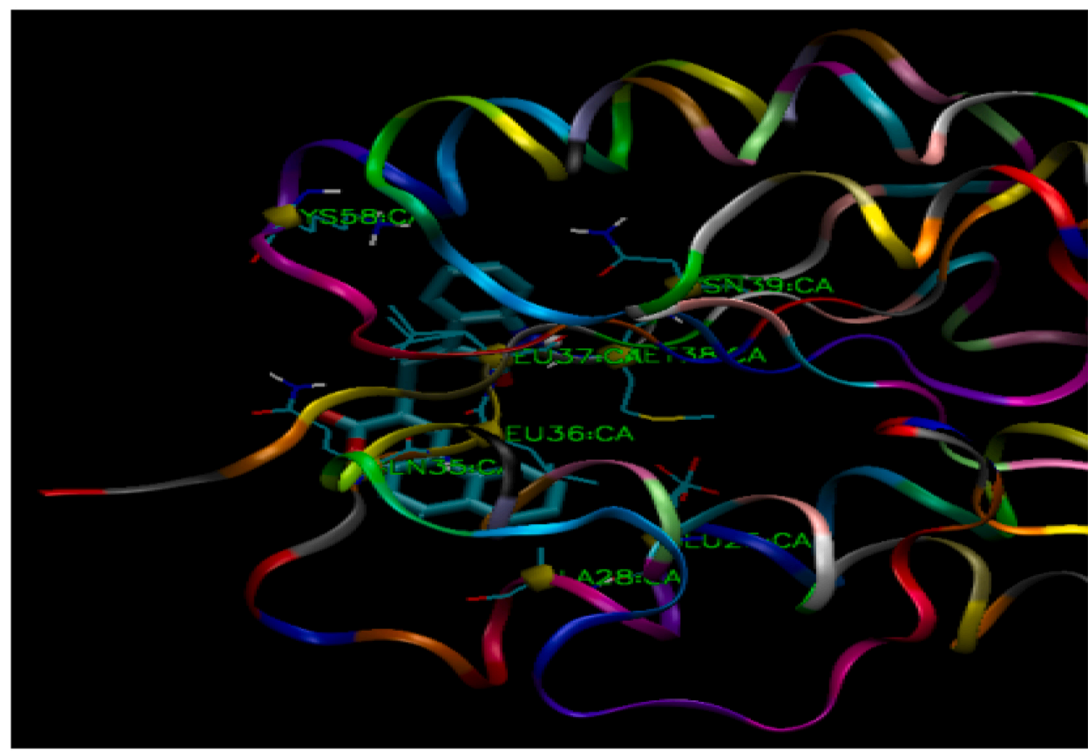

(b)

Fig. 2. Best affinity mode of docked compound 3OCE and 3OBC with 2-IPM.

$\bar{\nu}_{f}-\left(\right.$ in $\left.\mathrm{cm}^{-1}\right)$ represents maxima wavenumber in emission spectra. $\mathrm{n}$-solvent refractive index

$\varepsilon$ - solvent dielectric constant

Tables 1-3 summarize different photophysical parameters of compounds 3OCE and 3OBC in different solvents. Figs. 6-8 (a),(b), (a),(b), (a),(b) show the linear graphs for $\left(\bar{\nu}_{a}-\bar{\nu}_{f}\right) \mathrm{v} / \mathrm{sF}_{1}(\varepsilon, \mathrm{n}),\left(\bar{\nu}_{a}-\bar{\nu}_{f}\right) \mathrm{v} / \mathrm{s} \mathrm{F}_{2}(\varepsilon$, n) and $1 / 2\left(\bar{\nu}_{a}+\bar{\nu}_{f}\right) \mathrm{v} / \mathrm{s} \mathrm{F}_{3}(\varepsilon, \mathrm{n})$.Eqs. (1) - (3) are subjected to linear fitting to obtain slopes $m_{1}, m_{2}$ and $m_{3}$ respectively. These slopes are affected by the cavity radius size $(a)$ and change in the value of dipole moment of the solute upon excitation $\left(\Delta \mu=\mu_{e}-\mu_{g}\right)$. These can be represented as

$$
m_{1}=\frac{2\left(\mu_{e}-\mu_{g}\right)^{2}}{h c a^{3}}
$$




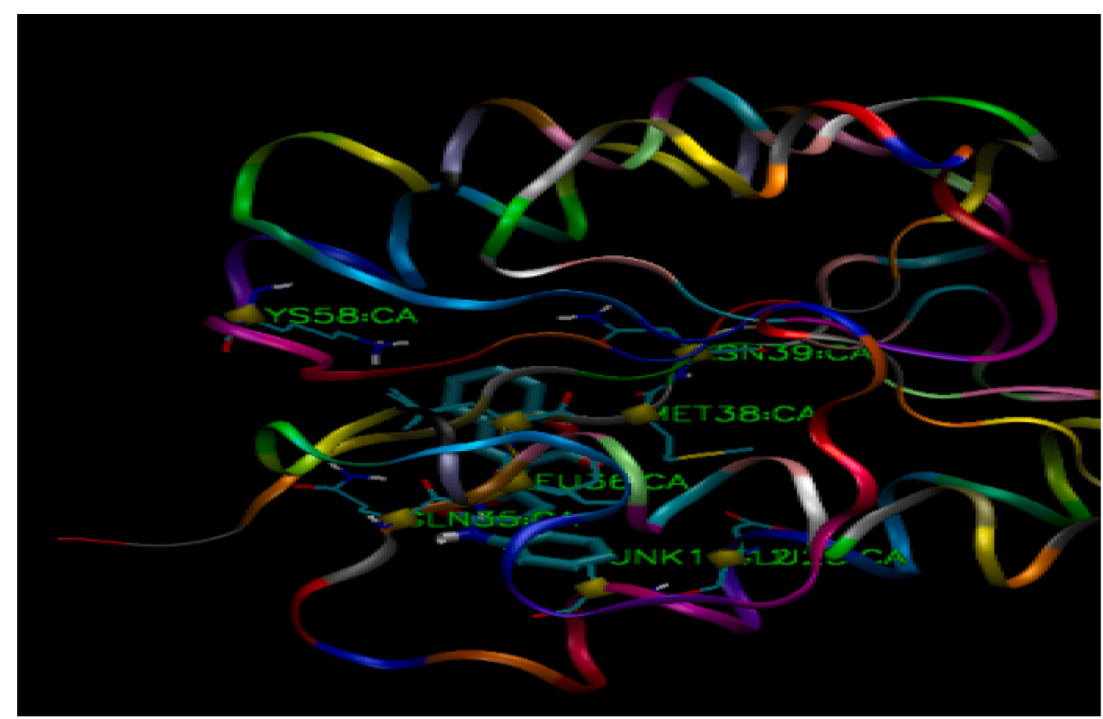

(a)

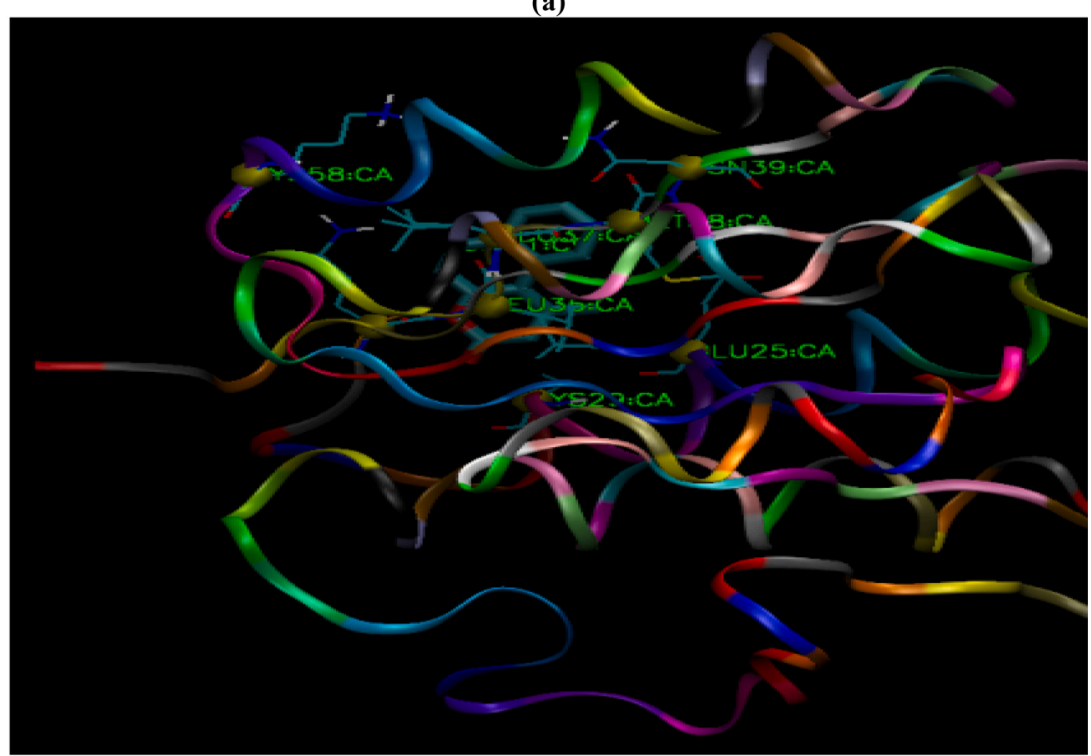

(b)

Fig. 3. Best affinity mode of docked compound 3OCE and 3OBC with 2-IPL.

$m_{2}=\frac{2\left(\mu_{e}-\mu_{g}\right)^{2}}{h c a^{3}}$

$m_{3}=\frac{2\left(\mu_{e}{ }^{2}-\mu_{g}{ }^{2}\right)}{h c a^{3}}$

where,

$\mu_{\mathrm{g}}$ refers to dipole moment at ground state, $\mu_{\mathrm{e}}$ is the dipole moment at excited state, h represents planck's constant, c is the speed of light, "a" represents the Onsager cavity radius [63] of the solutes. Table 4, depicts the solvents spectral shifts of 3OCE and 3OBC for various statistical correlations. Eqs. (10) - (12) is used for the determination of $\mu_{g}$ and $\mu_{e}$ provided that both are parallel to each other.

$$
\begin{aligned}
& \mu_{g}=\frac{m_{3}-m_{2}}{2}\left(\frac{h c a^{3}}{2 m_{2}}\right)^{\frac{1}{2}} \\
& \mu_{e}=\frac{m_{3}+m_{2}}{2}\left(\frac{h c a^{3}}{2 m_{2}}\right)^{\frac{1}{2}}
\end{aligned}
$$

and

$\mu_{e}=\frac{m_{2}+m_{3}}{m_{3}-m_{2}} \mu_{g} ; m_{3}>m_{2}$

In general, angle between $\mu_{g}$ and $\mu_{e}$ are collinear [51-53], otherwise, 


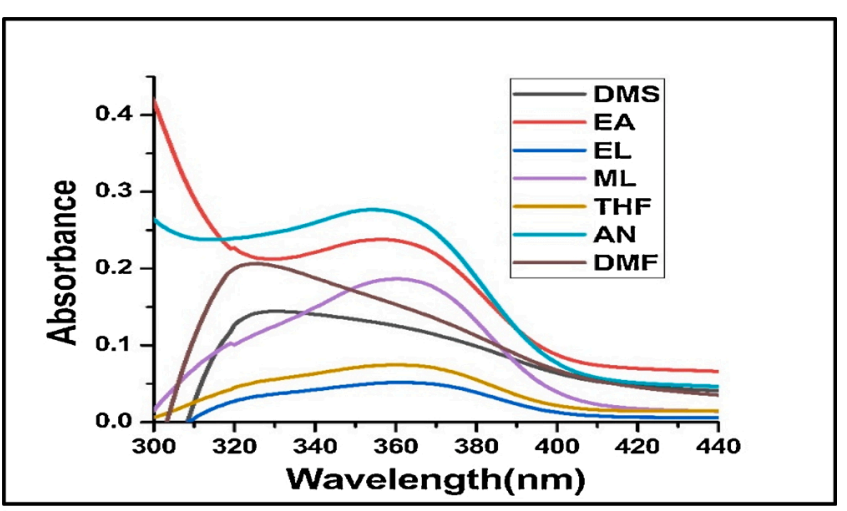

(a)

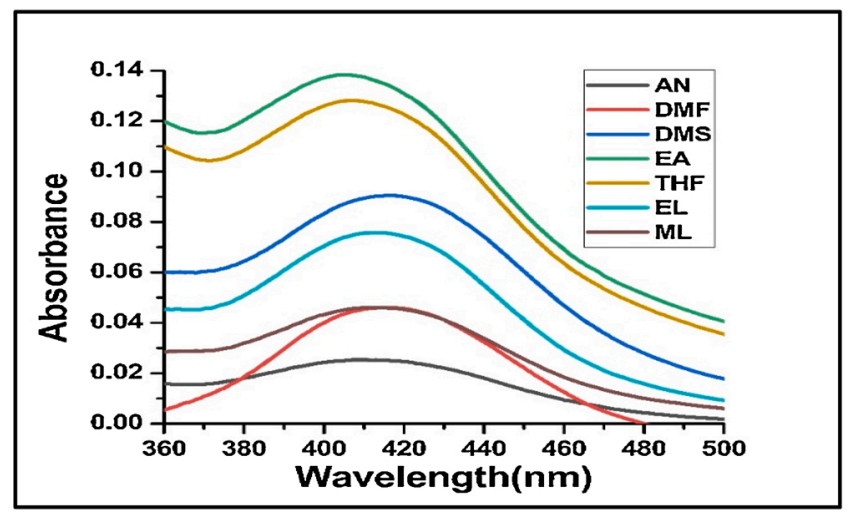

(b)

Fig. 4. Typical absorption spectrum of (a) 3OCE and (b) $30 B C$ in different solvents.

it is determined by equation given below

$\cos \varphi=\frac{1}{2 \mu_{g} \mu_{e}}\left[\left(\mu_{g}{ }^{2}+\mu_{e}{ }^{2}\right)-\frac{m^{(3)}}{m^{(2)}}\left(\mu_{e}{ }^{2}-\mu_{g}{ }^{2}\right)\right]$

Table 5 lists all different factors of dipole moment of compounds 3OCE and 3OBC. It is observed that, polar nature of solutes in ground state is lower than that in excited state which is indicated by $\mu_{e}$ being greater than $\mu_{g}$ but in case of $3 \mathrm{OBC}$ theoretical $\mu_{g}$ is high due to gas phase studies. Studies have shown that, after excitation there is an increase in dipole moment which helps to understand twisted intra-molecular charge transfer (TICT) character for excited species [20,29]. A good agreement was observed for $\mu_{g}$ and $\mu_{e}$ values estimated by the used methods. The difference between the values obtained from the spectral method and the theoretical calculation indicated that the occurrence of the TICT induced by the solvent effect is critical and the presence of some important factors such as hydrogen bonding interaction should be considered [66]. Whereas, angle between $\mu_{g}$ and $\mu_{e}$ is found to be $0^{\circ}$ for both 3OCE and 3OBC. It hereby confirms the dipole moments to be collinear. All the obtained results agree with the literatures $[9,16,24,28$, 29].

\subsubsection{Molecular-microscopic solvent polarity parameter $\left(\boldsymbol{E}_{T}^{N}\right)$}

Microscopic solvent polarity parameter $\left(\mathrm{E}_{\mathrm{T}}^{\mathrm{N}}\right)$ is employed to understand the effect of polarization and H-bonding effect on the spectral properties which are neglected in the above theories. The relevant empirical formula as derived by Reichardt [54 and 55] for the correlation of the spectral shift with $\mathrm{E}_{\mathrm{T}}^{\mathrm{N}}$, takes the form of

$\bar{\nu}_{a}-\bar{\nu}_{f}=11307.6\left[\left(\frac{\Delta \mu}{\Delta \mu_{b}}\right)^{2}\left(\frac{a_{B}}{a}\right)^{3}\right] E_{T}^{N}+$ constant

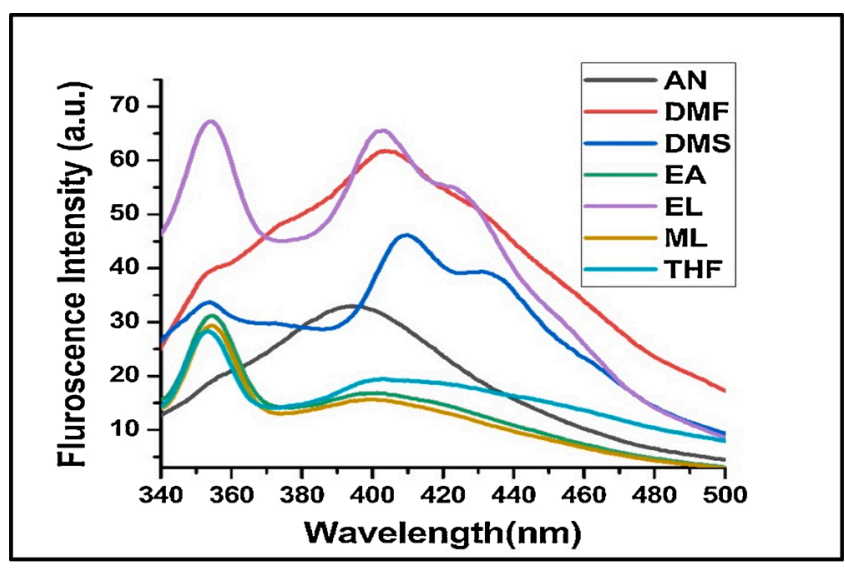

(a)

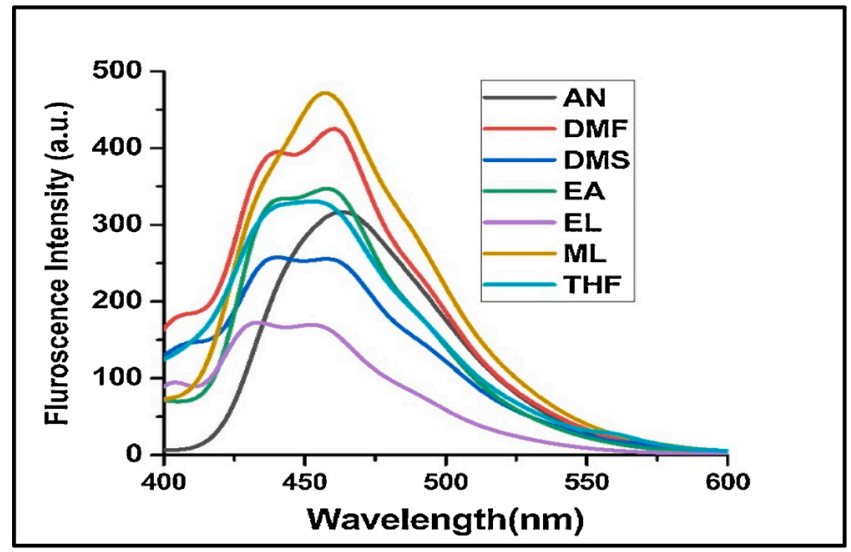

(b)

Fig. 5. Typical emission spectra for (a) 3OCE and (b) $30 B C$ in different solvents.

where $\Delta \mu_{b}=9 D$ and $a_{B}=6.2 \AA$ are the change in dipole moment after excitation and it is determined by the following Eq. (15) as given below

$\Delta \mu=\left(\mu_{e}-\mu_{g}\right)=\sqrt{\frac{(m \times 81)}{\left(\frac{6.2}{a}\right)^{3} \times 11307.6}}$

Where ' $m$ ' is the slope of the linear plot of Stoke's shift versus $E_{T}^{N}$ obtained from the linear fit of Eq. (14). The corresponding plots stokes shift $\left(\bar{\nu}_{a}-\bar{\nu}_{f}\right)$ against $E_{T}^{N}$, obtained from the relation (14) is shown in Fig. 9 (a),(b) for 3OCE and 3OBC compounds respectively. It is observed that, the increment in value of dipole moments in excited states is attributed to specific effect of solvent likely hydrogen bonding effect and complex formation etc. The difference in $\mu_{\mathrm{e}}$ values for variety of solutes may be because of their structural differences [54 and 55]

From the Table 5 we can say that, the $\mu_{\mathrm{e}}$ values are found to be more for 3OCE and and less for 3OBC compounds as compared to other models. This is due to the fact that, this model considers the specific solvent-solute interactions [29].

\subsection{Quantum chemical calculations}

\subsubsection{Theoretical approach for evaluating ground and excited state dipole} moments

Theoretically dipole moment at the ground state for 3OCE and 3OBC compounds is determined using DFT/B3LYP method with basis set of $6-311++\mathrm{G}(\mathrm{d}, \mathrm{p})$ [45-50] which is calculated as 4.566D for 3OCE and 5.270D for 3OBC compounds. The optimized geometry in ground state 
Table 1

Photo physical parameters of 3OCE in different solvents.

\begin{tabular}{|c|c|c|c|c|c|c|}
\hline Solvents & $\lambda_{a}(n m)$ & $\lambda_{e}(n m)$ & $\bar{\nu}_{a}\left(c m^{-1}\right)$ & $\bar{\nu}_{f}\left(\mathrm{~cm}^{-1}\right)$ & $\left(\bar{\nu}_{a}-\bar{\nu}_{f}\right)\left(\mathrm{cm}^{-1}\right)$ & $\left(\bar{\nu}_{a}+\bar{\nu}_{f}\right) / 2\left(\mathrm{~cm}^{-1}\right)$ \\
\hline ML & 360 & 465.00 & 27777.78 & 21505.38 & 6272.40 & 24641.58 \\
\hline AN & 355 & 457.00 & 28169.01 & 21881.84 & 6287.18 & 25025.43 \\
\hline EL & 362 & 454.00 & 27624.31 & 22026.43 & 5597.88 & 24825.37 \\
\hline DMF & 338 & 407.00 & 29585.80 & 24570.02 & 5015.77 & 27077.91 \\
\hline DMS & 340 & 408.00 & 29411.76 & 24509.80 & 4901.96 & 26960.78 \\
\hline THF & 362 & 420.00 & 27624.31 & 23809.52 & 3814.79 & 25716.92 \\
\hline EA & 357 & 402.00 & 28011.20 & 24875.62 & 3135.58 & 26443.41 \\
\hline
\end{tabular}

Table 2

Photo physical parameters of 3OBC in different solvents.

\begin{tabular}{|c|c|c|c|c|c|c|}
\hline Solvents & $\lambda_{a}(\mathrm{~nm})$ & $\lambda_{e}(\mathrm{~nm})$ & $\bar{\nu}_{a}\left(c m^{-1}\right)$ & $\bar{\nu}_{f}\left(\mathrm{~cm}^{-1}\right)$ & $\left(\bar{\nu}_{a}-\bar{\nu}_{f}\right)\left(\mathrm{cm}^{-1}\right)$ & $\left(\bar{\nu}_{a}+\bar{\nu}_{f}\right) / 2\left(\mathrm{~cm}^{-1}\right)$ \\
\hline ML & 411.00 & 465.00 & 24330.90 & 21505.38 & 2825.52 & 22918.14 \\
\hline AN & 415.00 & 467.00 & 24096.39 & 21413.28 & 2683.11 & 22754.83 \\
\hline EL & 414.00 & 466.00 & 24154.59 & 21459.23 & 2695.36 & 22806.91 \\
\hline DMF & 416.00 & 464.00 & 24038.46 & 21551.72 & 2486.74 & 22795.09 \\
\hline DMS & 415.00 & 462.00 & 24096.39 & 21645.02 & 2451.36 & 22870.70 \\
\hline THF & 416.00 & 461.00 & 24038.46 & 21691.97 & 2346.49 & 22865.22 \\
\hline EA & 415.00 & 461.00 & 24096.39 & 21691.97 & 2404.41 & 22894.18 \\
\hline
\end{tabular}

Table 3

Dielectric constant $(\varepsilon)$, refractive index $(n)$, solvent polarity functions, Microscopic solvent polarity parameter $\left(E_{T}^{N}\right)$ for 3OCE and 3OBC.

\begin{tabular}{lllllll}
\hline Solvents & $\varepsilon$ & $n$ & $F_{1}(\varepsilon, n)$ & $F_{2}(\varepsilon, n)$ & $F_{3}(\varepsilon, n)$ & $E_{N}^{T}$ \\
\hline ML & 33.7 & 1.328 & 0.309 & 0.858 & 0.652 & 0.762 \\
AN & 37.5 & 1.346 & 0.305 & 0.863 & 0.667 & 0.46 \\
EL & 24.35 & 1.361 & 0.289 & 0.812 & 0.652 & 0.654 \\
DMF & 38.25 & 1.43 & 0.275 & 0.839 & 0.711 & 0.404 \\
DMS & 47.24 & 1.479 & 0.263 & 0.841 & 0.744 & 0.444 \\
THF & 7.58 & 1.407 & 0.210 & 0.549 & 0.551 & 0.207 \\
EA & 6.08 & 1.372 & 0.201 & 0.493 & 0.499 & 0.228 \\
\hline
\end{tabular}

for 3OCE and 3OBC is shown in Fig. 10 (a),(b). The direction of dipole moment is represented by direction of the arrow head. On comparing the experimental and theoretical dipole moments in ground state, a huge discrepancy was found. However, the existence of such discrepancy might be as a consequence of consideration of gas phase and also a possibility due to exclusion of interaction between solute and solvent through the theoretical approach.

\subsubsection{Analyzing the frontier molecular orbital}

Frontier molecular orbital analysis is done using computational Chemistry for determining number of active sites, chemical reactivity and kinetic stability of the molecules. HOMO represents ability to loose electrons and LUMO represents ability to gain electrons for the heterocyclic compounds. Charge transfer properties of heterocyclic compounds is studied through this analysis. The analysis [20] uses DFT/B3LYP with basic set $6-311++G(d, p)$. The Fig. 11(a) and (b) shows HOMO-LUMO three dimensional plots of 3OCE and 3OBC molecules respectively.

Small energy gap corresponds to a soft molecule indicating that the compounds are more reactive where large energy gap corresponds to hard molecule and molecular stability of the measurer. Koopmans' theorem states ionization potential (IP) and electron affinity (EA) as EA $=-\mathrm{E}_{\mathrm{LUMO}}$ and IP $=-\mathrm{E}_{\text {HOMO }}[57]$. We use $\chi=[(\mathrm{IP}+\mathrm{EA}) / 2]$ to determine Electronegativity $(\chi)$ and $\mathrm{V}=-[(\mathrm{IP}+\mathrm{EA}) / 2]$ to calculate chemical potential (V) [20]. Chemical reactivity is determined through chemical softness (S) and chemical stability is measured by chemical hardness. Chemical softness is given as inverse of chemical hardness (i.e $S=\frac{1}{\eta}$ ) and chemical hardness $(\eta)$ is given as $\eta=$ [(IP-EA)/2] [34,43]. The relation, $\omega$ $=\frac{\mu^{2}}{2 \eta}$ is used for determining the eletrophilicity index which informs

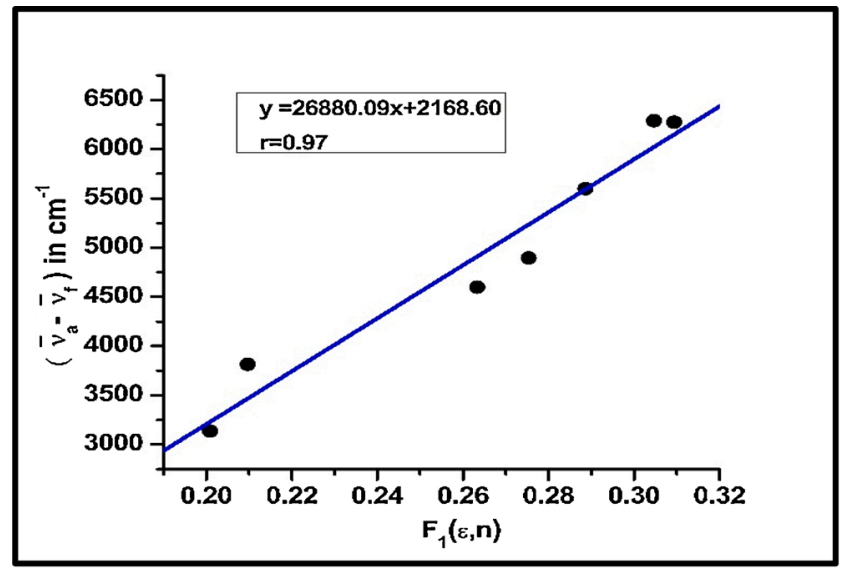

(a) $30 \mathrm{CE}$

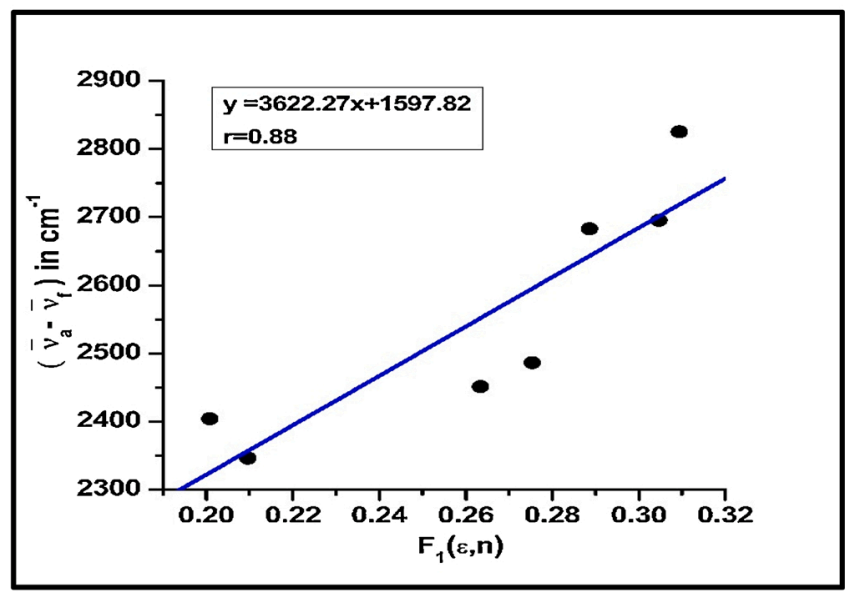

(b) $30 \mathrm{OBC}$

Fig. 6. The variation of Stoke's shift with $\mathrm{F}_{1}(\varepsilon, \mathrm{n})$ using Lippert equation for 6 (a)3OCE and 6(b)3OBC. 


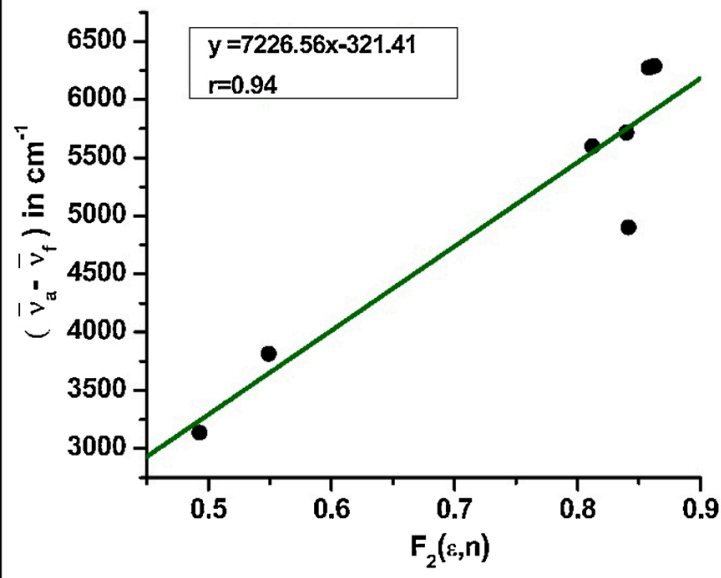

(a) $30 \mathrm{CE}$

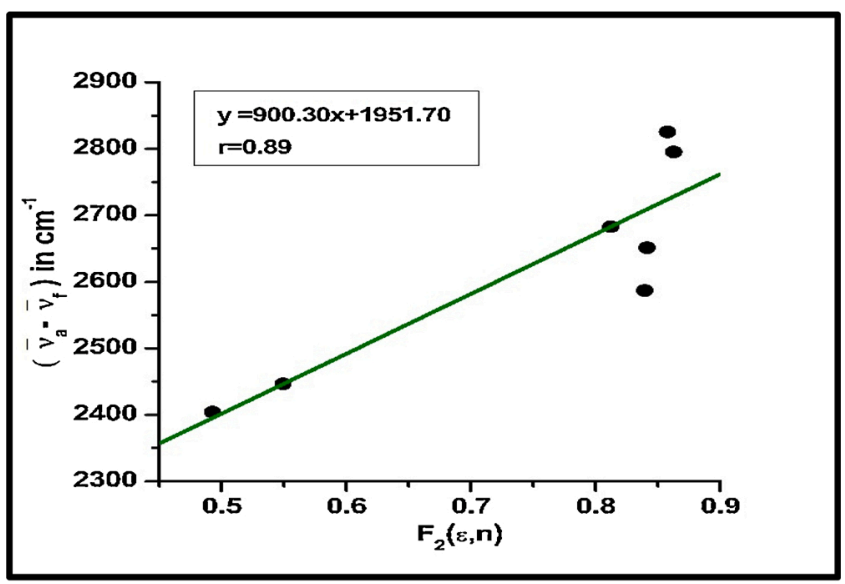

(b) $30 \mathrm{OBC}$

Fig. 7. The variation of Stoke's shift with $\mathrm{F}_{2}(\varepsilon, \mathrm{n})$ using Bakshiev's equation for 7(a) 3OCE and 7(b) 3OBC.

about the electrophilic property of a compound [20]. Table 6 shows the determined frontier molecular orbital and the related molecular properties for 3OCE and 3OBC compounds. The energy gap for 3OCE is observed to be $2.995 \mathrm{eV}$ and $2.966 \mathrm{eV}$ for $3 \mathrm{OBC}$. There is a possibility of nucleophilic and electrophilic attack which is indicated by low values of electron affinity and higher values of ionization potential for 3OCE and 3OBC compounds [34].

\subsubsection{Molecular Electrostatic Potentials (MEP) and analysis of contour} map

Molecular electrostatic potentials (MEPs) is the cloud of charged particles that surround molecules.The nucleophilic and electrophilic property for the molecules is identified by colored regions shown.

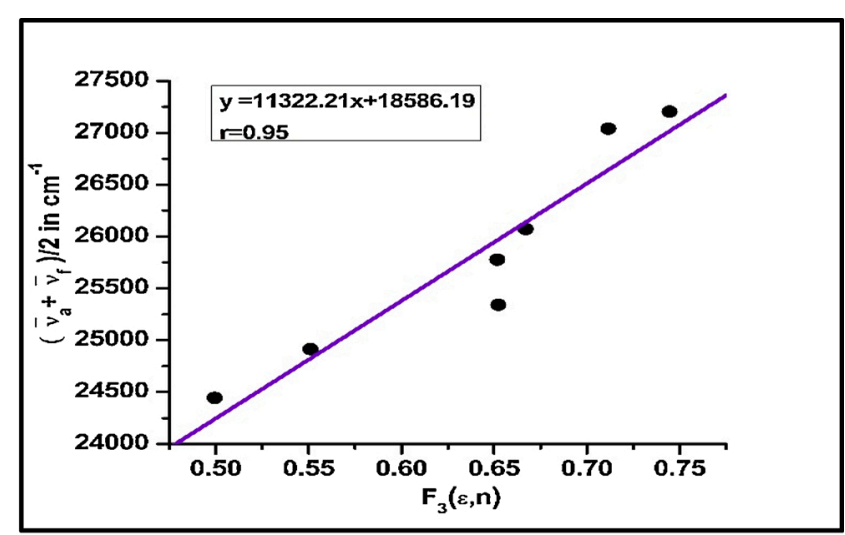

(a) $30 \mathrm{CE}$

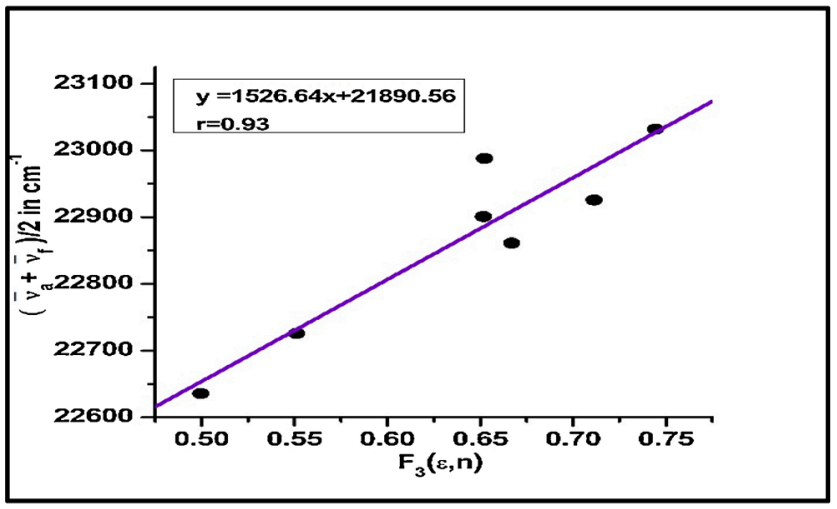

(b) $30 \mathrm{OBC}$

Fig. 8. The variation of arithmetic means of Stoke's shift with $F_{3}(\varepsilon, n)$ using Kawski- Chamma-Viallet's equation for 8(a) 3OCE and 8(b) 3OBC.

Table 4

Statistical treatment of the correlations of solvents spectral shifts of 3OCEand 3ОВC.

\begin{tabular}{|c|c|c|c|c|c|}
\hline Compounds & Method & Slope & Intercept & $\begin{array}{l}\text { Correlation } \\
\text { factor ' } r \text { ' }\end{array}$ & $\begin{array}{l}\text { Number } \\
\text { of data } \\
\text { (N) }\end{array}$ \\
\hline \multirow[t]{4}{*}{ 3OCE } & $\begin{array}{l}\text { Lippert } \\
\text { Correlation }\end{array}$ & 26880.09 & 2468.60 & 0.97 & 7 \\
\hline & $\begin{array}{l}\text { Bakhshiev's } \\
\text { Correlation }\end{array}$ & 7226.56 & -321.41 & 0.94 & 7 \\
\hline & $\begin{array}{l}\text { Kawaski- } \\
\text { Chamma- } \\
\text { Viallet } \\
\text { Correlation }\end{array}$ & 11322.21 & 18586.19 & 0.95 & 7 \\
\hline & $\begin{array}{l}\text { Reichards } \\
\text { Correlation }\end{array}$ & 5072.86 & 2512.75 & 0.93 & 7 \\
\hline \multirow[t]{4}{*}{ 3ОВC } & $\begin{array}{l}\text { Lippert } \\
\text { Correlation }\end{array}$ & 3622.27 & 1597.82 & 0.88 & 7 \\
\hline & $\begin{array}{l}\text { Bakhshiev's } \\
\text { Correlation }\end{array}$ & 900.30 & 1951.70 & 0.89 & 7 \\
\hline & $\begin{array}{l}\text { Kawaski- } \\
\text { Chamma- } \\
\text { Viallet } \\
\text { Correlation }\end{array}$ & 1526.64 & 21890.56 & 0.93 & 7 \\
\hline & $\begin{array}{l}\text { Reichards } \\
\text { Correlation }\end{array}$ & 180.50 & 2575.39 & 0.91 & 7 \\
\hline
\end{tabular}


Table 5

Ground state and excited state dipole moments of 3OCE and 3OBC.

\begin{tabular}{|c|c|c|c|c|c|c|c|c|c|c|c|c|}
\hline Compound & Radius 'a' $\left(A^{0}\right)$ & $\mu_{g}^{a}(D)$ & $\mu_{g}^{b}(D)$ & $\mu_{\mathrm{e}}{ }^{\mathrm{c}}(\mathrm{D})$ & $\mu_{\mathrm{e}}^{\mathrm{d}}(\mathrm{D})$ & $\mu_{\mathrm{e}}^{\mathrm{e}}(\mathrm{D})$ & $\mu_{\mathrm{e}}^{\mathrm{f}}(\mathrm{D})$ & $\mu_{\mathrm{e}}^{\mathrm{g}}(\mathrm{D})$ & $\Delta \mu^{\mathrm{h}}$ & $\Delta \mu^{\mathrm{i}}$ & $\left(\frac{\mu_{\mathrm{e}}}{\mu_{\mathrm{g}}}\right)^{\mathrm{j}}$ & $\Phi^{\mathrm{k}}$ \\
\hline 3OCE & 3.994 & 4.566 & 1.917 & 8.681 & 14.963 & 8.681 & 8.681 & 5.034 & 6.764 & 3.117 & 4.529 & $0^{\circ}$ \\
\hline 3OBC & 4.202 & 5.271 & 0.896 & 3.473 & 6.064 & 3.473 & 3.473 & 1.531 & 2.576 & 0.634 & 3.875 & $0^{\circ}$ \\
\hline
\end{tabular}

Debye (D) $=3.33564 \times 10-30 \mathrm{~cm}=10^{-18}$ esu cm.

$j$ The ratio of excited state and ground state dipole moment.

${ }^{\mathrm{k}_{\mathrm{T}}}$ The angle between ground state and excited state dipole moments calculated using Eq.(13).

a The ground states dipole moments calculated using Gaussian software.

b The ground states dipole moments calculated using Eq.(7).

c The excited states dipole moments calculated using Eq.(8).

d The experimental excited states dipole moments calculated from Lippert's equation.

e The experimental excited states dipole moments calculated from Bakshiev's equation.

${ }^{f}$ The experimental excited states dipole moments calculated from Kawaski-Chamma-Viallet equation.

$\mathrm{g}$ The excited states dipole moments calculated from $E_{N}^{T}$ equation.

h The change in dipole moments for $\mu_{\mathrm{e}}$ and $\mu_{\mathrm{g}}$.

i The change in dipole moments calculated from Eq.(16).

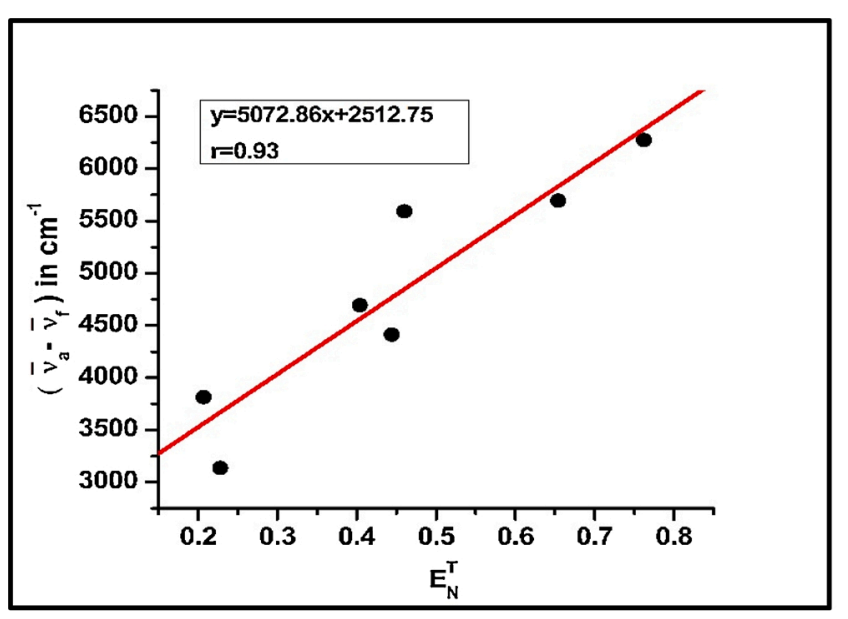

(a) $30 \mathrm{CE}$

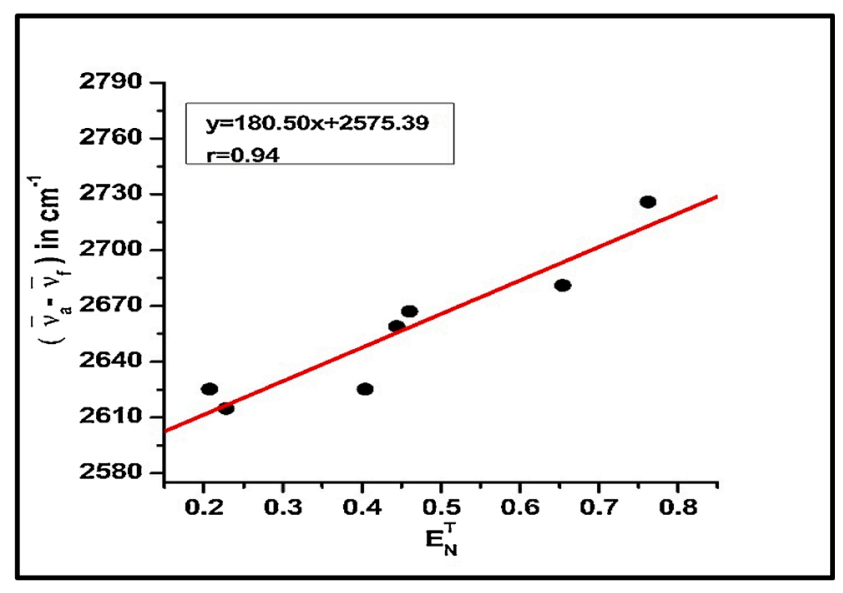

(b) $30 B C$

Fig. 9. The variation of Stoke's shift with $E_{T}^{N}$ for 9(a) 3OCE and 9(b) 3OBC.

Electrostatic potentials, V(r), of the molecules can be given by Eqn. (16) [34]

$V(r)=\sum\left[\frac{Z_{R}}{\left|R_{A}-r\right|}\right]-\int\left[\frac{\rho\left(r^{\prime}\right) d r^{\prime}}{\left|r^{\prime}-r\right|}\right]$
$Z_{R}$ - charge of nucleus A located at $R_{A}$

$\rho\left(r^{\prime}\right)$ - represents the solute's electron density function

$r^{\prime}$ - refers to the dummy's integration variable

Contour maps for 3OCE and 3OBC compounds is shown in Fig. 12 (a) and (b). Electrophilic (electron rich) reactivity is represented by the dark red colored region surrounding the oxygen atom and nucleophilic (electron deficient) reactivity is shown by the dark blue colored region surrounding the hydrogen atom of 3OCE and $3 \mathrm{OBC}$ compounds. It is observed that, color code of MEP diagram lies between -0.0594 a. u (Dark red) and 0.0594 a. u. (Dark blue) for 3OCE compound and -0.06118 a. u (Dark red) and 0.06118 a. u (Dark blue) for 3OBC compound. Fig. 13(a) and (b) shows the contour map for molecular electrostatic potential surface of $30 \mathrm{OCE}$ and $3 \mathrm{OBC}$ compounds. In addition, it confirms for the positive and negative regions of the molecules in agreement with total electron density surface. Available sites for nucleophilic and electrophilic reaction is shown by MEP as well as contour analysis.

\subsubsection{Evaluating atomic charges}

The concept of charge transfer and atomic charges is used in explanation of reactivity and molecular behavior in quantum chemistry. B3LYP methods with basis level of $6-311++G(d, p)$ in Mulliken population study is used for evaluating the atomic charge number on each atom the compounds under investigation [20]. Mulliken charge distribution for 30CE and 3OBC compounds is shown in Fig. 14 (a) and (b). Table 7(a) and (b) lists down the Mulliken atomic charge distribution for both the compounds. A total 35 atoms for 3OCE and 41 atoms for 3OBC are present.

\subsubsection{Fukui function analysis}

In heterocyclic compounds, Fukui function is used mostly for reactive indicators. The representation of Fukui function is given by Eqn. (17)

$\mathrm{F}(\mathrm{r})=\frac{\partial \rho(r)}{\partial N}$

where,

$r$ is the external potential exerted by nucleus

$\mathrm{N}$ refers to the number of electrons

$\rho(\mathrm{r})$ represents the electronic density

Upon accepting or donating electrons in heterocyclic molecules, the identification of electron density and reactive sites at given position is done by Fukui [56-62].

Given below is the definition for possible atomic Fukui functions on jth atom site:

where, 


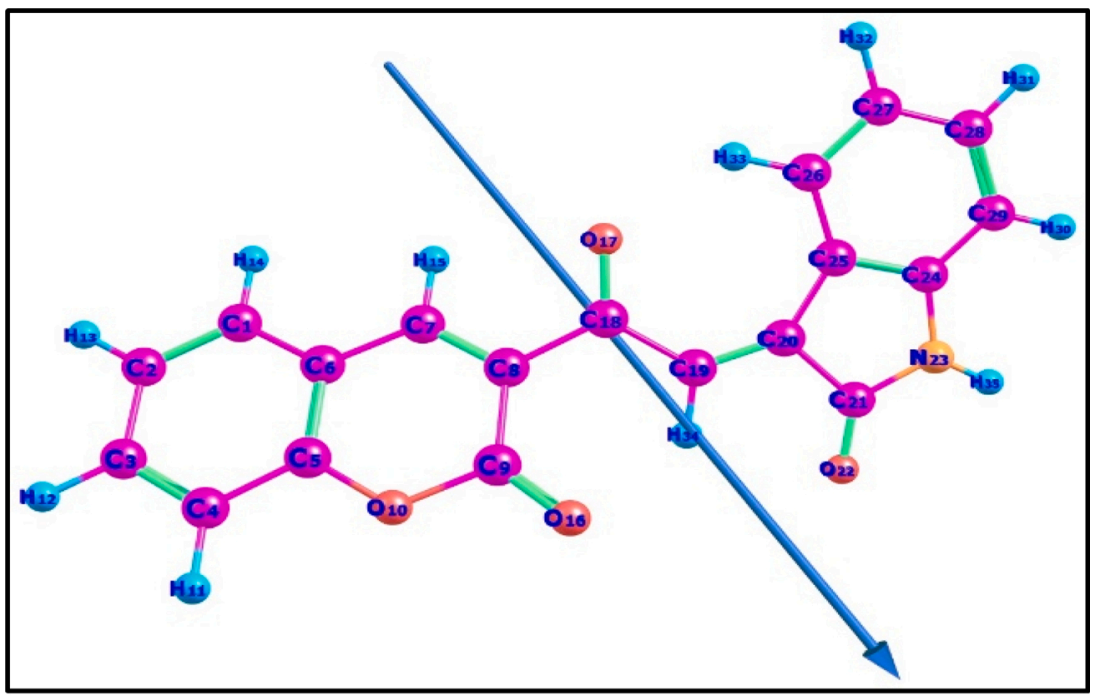

(a) $30 \mathrm{CE}$

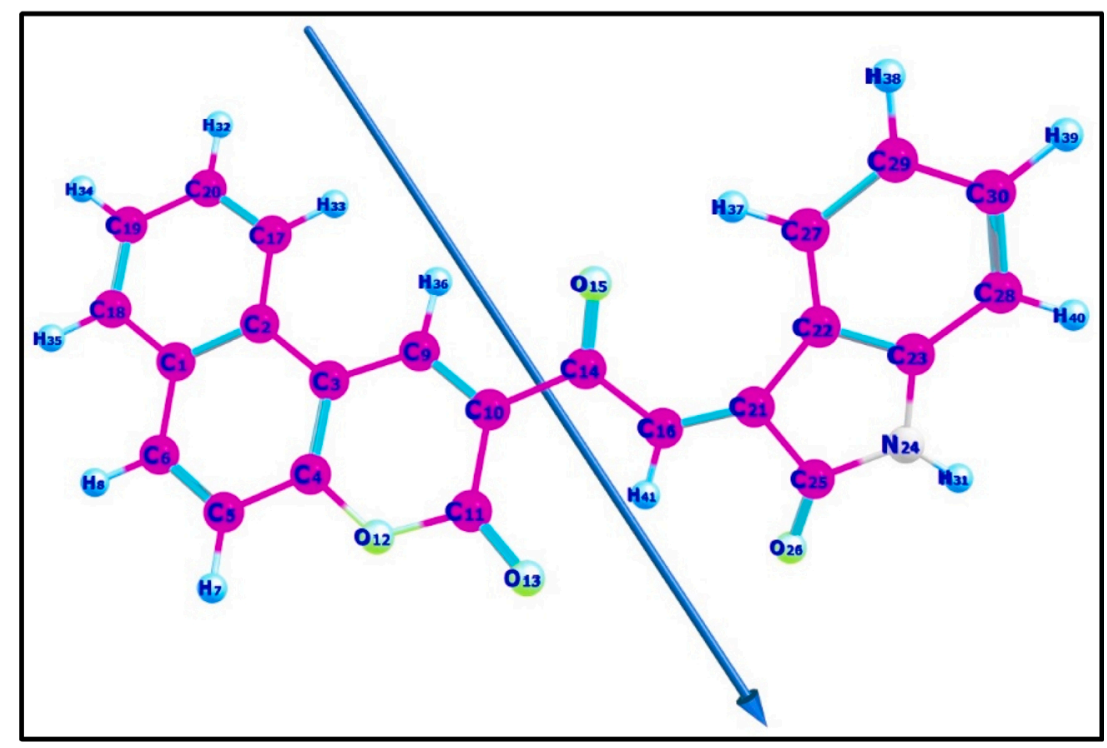

(b) 3OBC

Fig. 10. Ground state optimized molecular geometries of 10 (a) $3 \mathrm{OCE}$ and 10 (b) $3 \mathrm{OBC}$. The arrow indicates the direction of the dipole moment.

$f_{j}^{-}=\left[q_{j}(N)-q_{j}(N-1)\right]$

$f_{j}^{+}=\left[q_{j}(N+1)-q_{j}(N)\right]$

$f_{j}^{0}=\left[q_{j}(N+1)-q_{j}(N-1)\right] / 2$

$f_{j}^{+}(r)$ - nucleophilic Fukui function $f_{j}^{-}(r)$ - electrophilic Fukui function $f_{j}^{0}$ gives the Fukui function for free radical

qj represents the atomic charge at the jth atomic site

Eqn. (21) below shows calculation of Fukui function as an intramolecular reactivity index [56-63] from NBO charges

$\int f(r) d r=1$

In this study, calculations are performed using ground state with double multiplicity at DFT/B3LYP $6-311++\mathrm{G}(\mathrm{d}$, p) basis set for single point energy in the anionic and cationic form of the 3OCE and 3OBC 


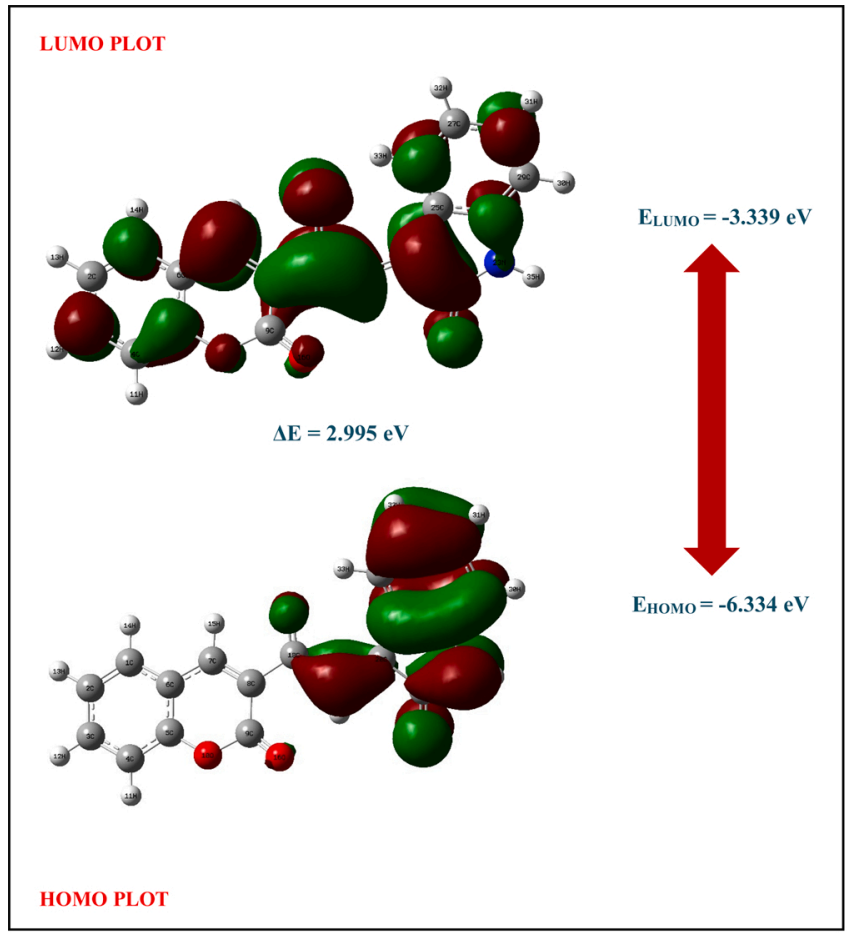

(a) $30 \mathrm{CE}$

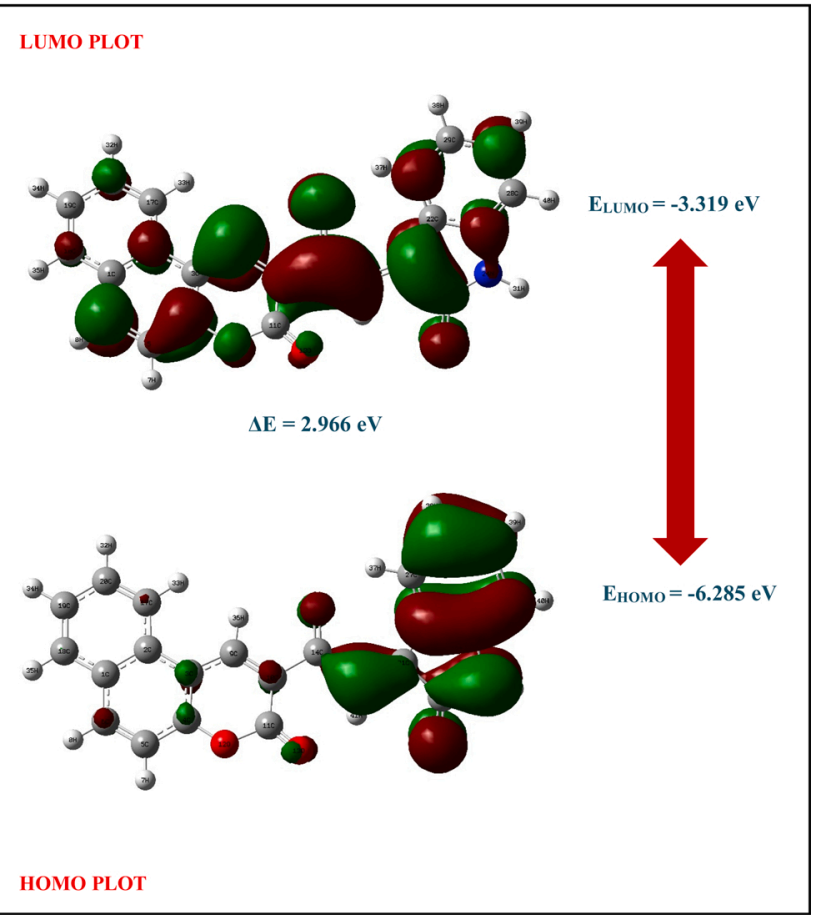

(b) $30 B C$

Fig. 11. HOMO-LUMO Structure of 11 (a) 3OCE and 11 (b) $30 B C$.

Table 6

The calculated FMOs and related molecular properties values of the 3OCE and 3OBC.

\begin{tabular}{lll}
\hline Molecular properties & $\begin{array}{l}\text { Energy (in eV) } \\
\text { for 3OCE }\end{array}$ & $\begin{array}{l}\text { Energy (in eV) } \\
\text { for 3OBC }\end{array}$ \\
\hline HOMO & -6.334 & -6.285 \\
LUMO & -3.339 & -3.319 \\
E $_{\text {HOMO-E }}$ LUMO & 2.995 & 2.966 \\
Ionization potential (IP) & 6.334 & 6.285 \\
Electron affinity(EA) & 3.339 & 3.319 \\
Electronegativity $(\chi)$ & 4.837 & 4.802 \\
Hardness( $\eta)$ & 1.498 & 1.483 \\
Softness(S) & 0.668 & 0.674 \\
Chemical potential $(\mu)$ & -4.837 & -4.802 \\
Electrophilicity index $(\omega)$ & 7.811 & 7.776 \\
\hline
\end{tabular}

compounds. Table 8(a) and (b) shows the determined values of local reactivity descriptors such as Fukui functions $\left(\mathrm{f}_{\mathrm{k}}^{+}, \mathrm{f}_{\mathrm{k}}, \mathrm{f}_{\mathrm{k}}{ }^{\circ}\right)$, local electrophilicity indices $\left(\omega_{\mathrm{k}}^{+}, \omega_{\mathrm{k}}^{-}, \omega_{\mathrm{k}}{ }^{\circ}\right)$ and local softness $\left(\mathrm{S}_{\mathrm{k}}^{+}, \mathrm{S}_{\mathrm{k}}^{-}, \mathrm{S}_{\mathrm{k}}{ }^{\circ}\right)$. These descriptors are based on electron density. For 3OCE, most of the nucleophilic reactive atoms were observed to follow the order of $\mathrm{O} 22>$ $\mathrm{C} 27>\mathrm{N} 23>\mathrm{H} 32$. Atoms $\mathrm{C} 27$ and $\mathrm{H} 32$ are identified to be high reactive site for a nucleophilic attack and are also present in benzene ring. In the case of 3OBC, electrophilic reactive atoms are found to follow C20 > $\mathrm{O} 17>\mathrm{C} 7>\mathrm{H} 31$ order. Atoms $\mathrm{C} 20, \mathrm{O} 17$ and $\mathrm{H} 31$ are highly reactive site for an electrophilic attack and are found to be present in the benzene. However O22, C20, C27 and H31 atoms are identified to be favorable sites for radical attack. In Table 8 (b), it is clearly shown that for 3OBC, atoms $\mathrm{C} 29, \mathrm{H} 38$ and $\mathrm{H} 39$ are identified as reactive region being present in the benzene ring for nucleophilic attack and atoms C9, C10, C6 and $\mathrm{H} 8$ for electrophilic attack being identified as reactive region. And atoms C21, O26, 015 andC9 are favorable sites for the radical attack.

\subsubsection{Analysis of natural bonding orbital (NBO)}

The analysis of natural bonding orbital (NBO) provides an important inter and intra molecular bonding for identifying hyper-conjugative interactions or charge transfer probability $[48,49]$. NBO 5.0 software is used for studying re-hybridization of 3OCE and 3OBC. Also Gaussian 9 W software is used for determining delocalization of electron density and intra-molecular charge distribution inside the molecule. Bonding and anti-bonding interactions are analyzed through NBO analysis in a qualitative way. The perturbation energies E(2) is given by the Eqn. (22) [41-44].

$\mathrm{E}(2)=\Delta \mathrm{Eij}=\mathrm{qi} \frac{F^{2}(i j)}{\left(E_{i}-E_{j}\right)}$

Where

$F_{(i j)}$ shows off-diagonal matrix element for NBO Fock matrix element $\mathrm{q}_{\mathrm{i}}$ represents the occupancy of donor orbital

$\mathrm{E}_{\mathrm{i}}$ and $\mathrm{Ej}$ are the energies of diagonal elements,

Various parameters of NBO basis for both the compounds is depicted in both the compounds. Table 9(a) and (b). Two donors and two acceptors are observed to be available for different perturbation energy transitions such as C21- N23 $\rightarrow$ C27-C28 (395.09 kj/mol, $\left.\pi \rightarrow \pi^{*}\right)$, N23$\mathrm{C} 24 \rightarrow \mathrm{C} 8-\mathrm{C} 9\left(311.66 \mathrm{kj} / \mathrm{mol}, \pi \rightarrow \pi^{*}\right), \mathrm{N} 23-\mathrm{H} 35 \rightarrow \mathrm{C} 8-\mathrm{C} 9(606.52 \mathrm{kj} / \mathrm{mol}$, $\left.\pi \rightarrow \pi^{*}\right)$ and for 3OBC, C22-C27 $\rightarrow$ C23-C28 $\left(24.05 \mathrm{kj} / \mathrm{mol}, \pi \rightarrow \pi^{*}\right)$, C29$\mathrm{C} 30 \rightarrow \mathrm{C} 22-\mathrm{C} 27 \quad\left(23.15 \mathrm{kj} / \mathrm{mol}, \pi \rightarrow \pi^{*}\right), \quad \mathrm{C} 5-\mathrm{C} 6 \rightarrow \mathrm{C} 3-\mathrm{C} 4 \quad(21.32 \mathrm{kj} / \mathrm{mol}$, $\left.\pi \rightarrow \pi^{*}\right)$ are the most probable transitions for 3OCE. From these transitions we can say that transitions happen only within phenyl ring and major contribution is by $\pi$ electrons which are having Intramolecular hyper conjugative interactions. However in case of $3 \mathrm{OBC}$ molecule, transition takes place from the lone pair of $\mathrm{O} 13$ to $\sigma^{*}(\mathrm{C} 11-\mathrm{O} 12)$ and $\mathrm{O} 12$ to $\sigma^{*}(\mathrm{C} 11-\mathrm{O} 13)$ which is responsible for the stabilization of the system. Further, $\pi \rightarrow \pi^{*}$ transition is responsible for the NLO activity of 3OCE and 3OBC compounds.

\subsubsection{Analysis of molecular docking}

The molecular docking for both compounds 3OCE and 3ОBC were carried out using AutoDock. The crystal structure of galactose binding 


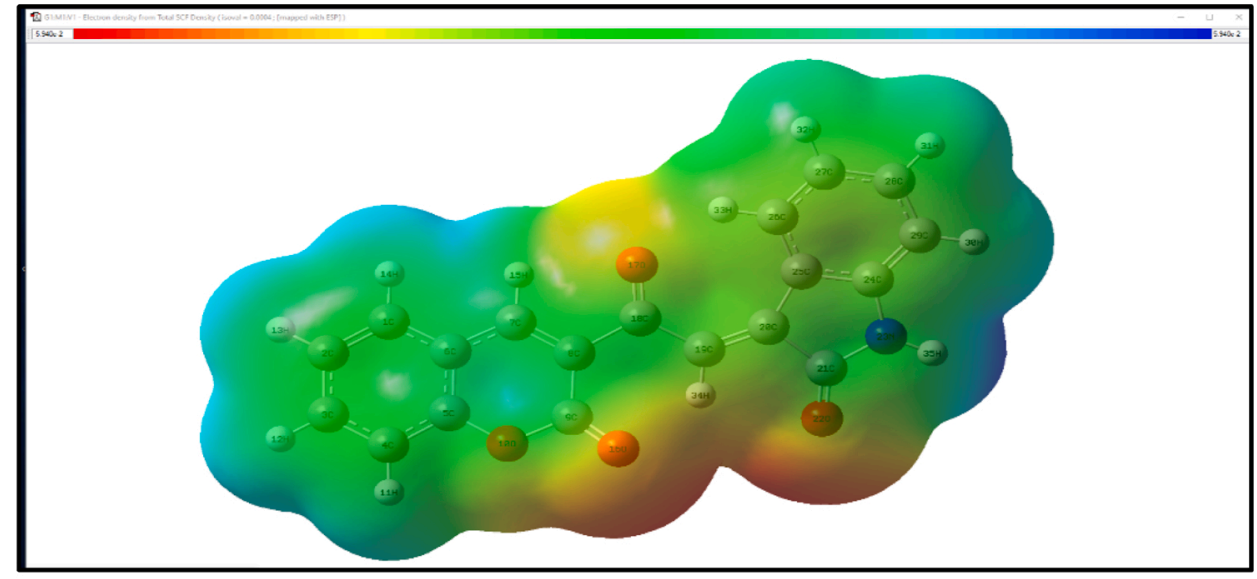

(a) $30 \mathrm{CE}$

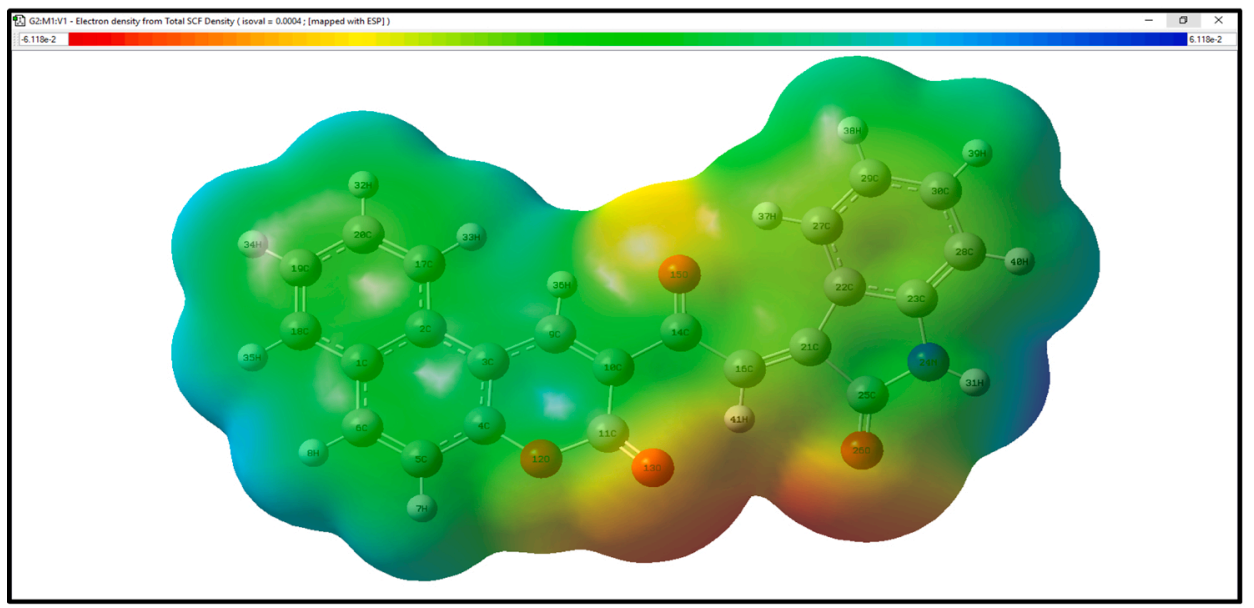

(b) $30 B C$

Fig. 12. The total electron density mapped with the MEP surface for 12 (a) $3 \mathrm{OCE}$ and 12 (b) $3 \mathrm{OBC}$.

periplasmic protein (PDB ID: 2IPM and 2IPL) was retrieved from protein data bank, pre-processing and preparation of the protein for docking was performed by using VMD 1.9.3. The molecular docking for both compounds $30 \mathrm{OCE}$ and $3 \mathrm{OBC}$ were carried out using Auto Dock Tools version 1.5.6 software. The binding affinity mode of docked compound 3OCE and 3OBC with 2-IPM and IPL are as shown in Fig. 2(a) \& (b) and Fig. 3 (a) \& (b) respectively. Interaction of 2IPM and 2IPL protein for both compounds 3OCE and $30 B \mathrm{BC}$ with docked energy parameters as shown Table 10. These parameters infer that the coumarin compounds will bind strongly with periplasmic proteins of the blood $[64,65]$. 


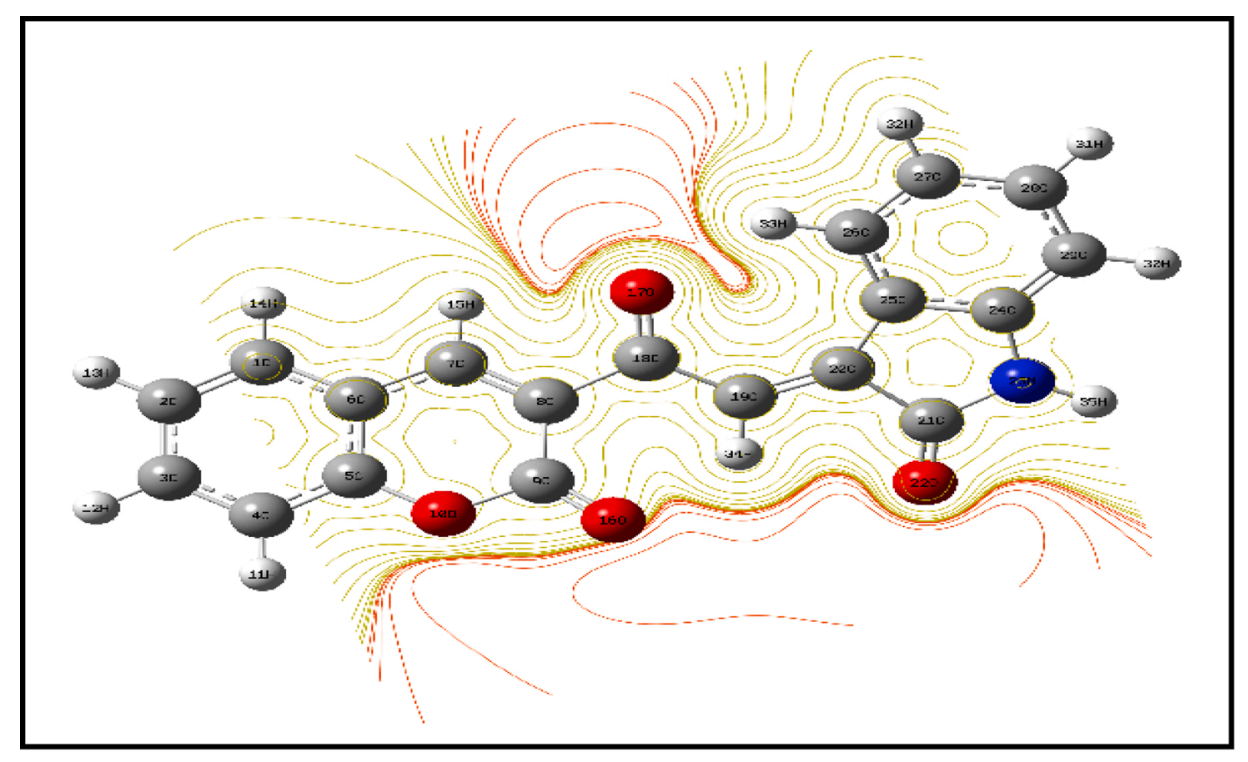

(a) $30 \mathrm{CE}$

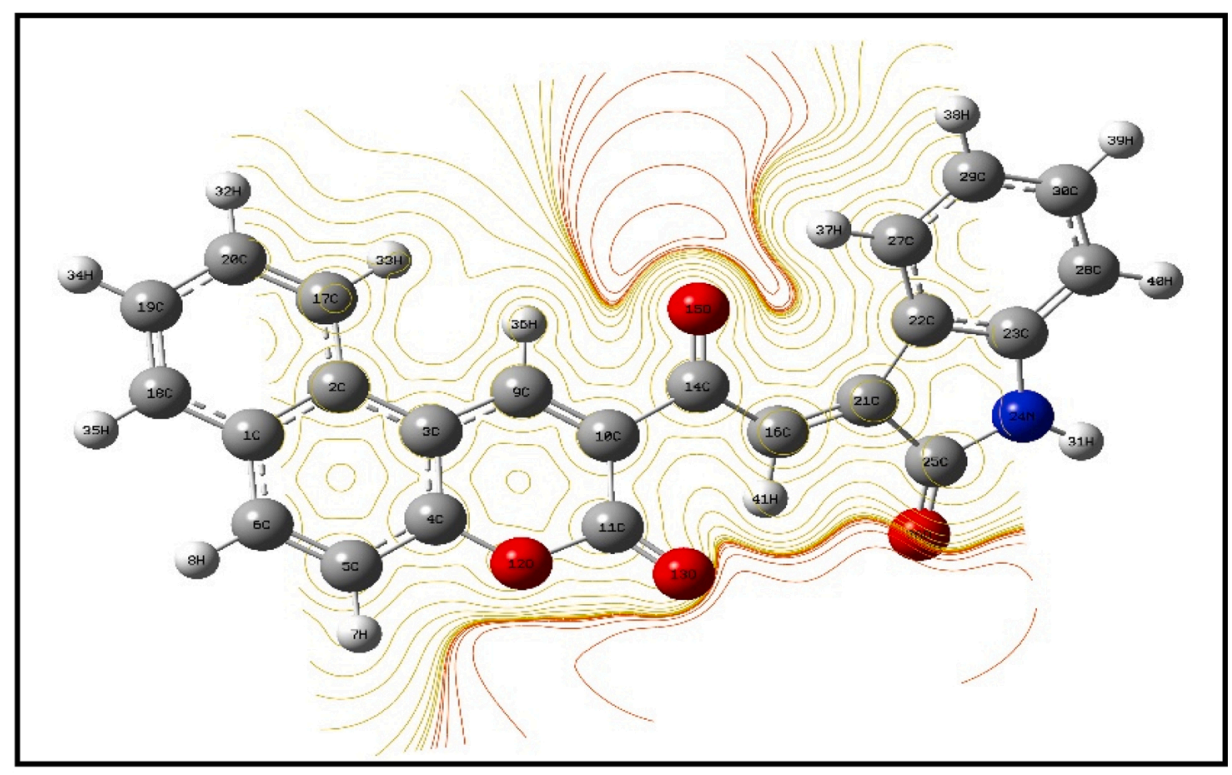

(b) 3OBC

Fig. 13. The contour map of molecular electrostatic potential surface for 13 (a) $3 \mathrm{OCE}$ and 13 (b) $3 \mathrm{OBC}$. 


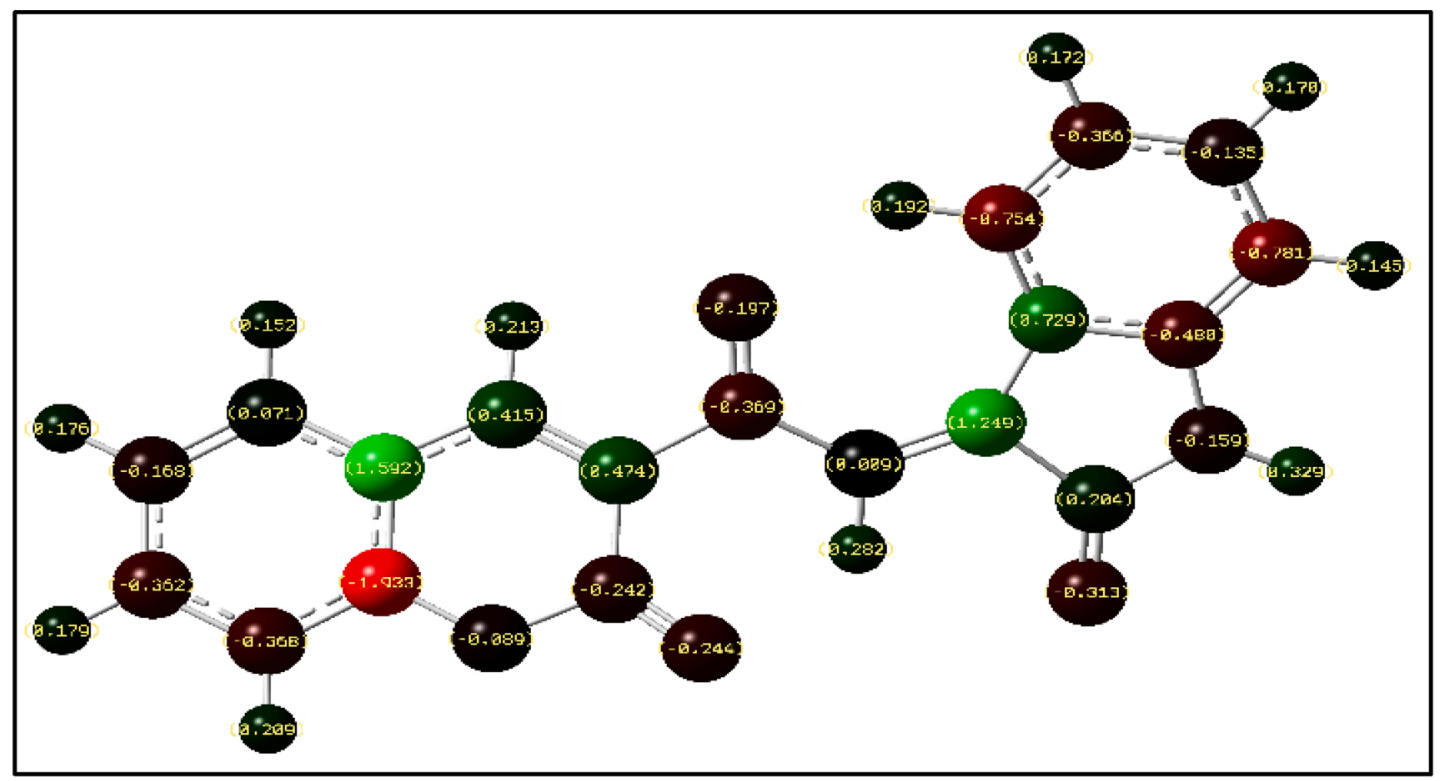

(a) $30 \mathrm{CE}$

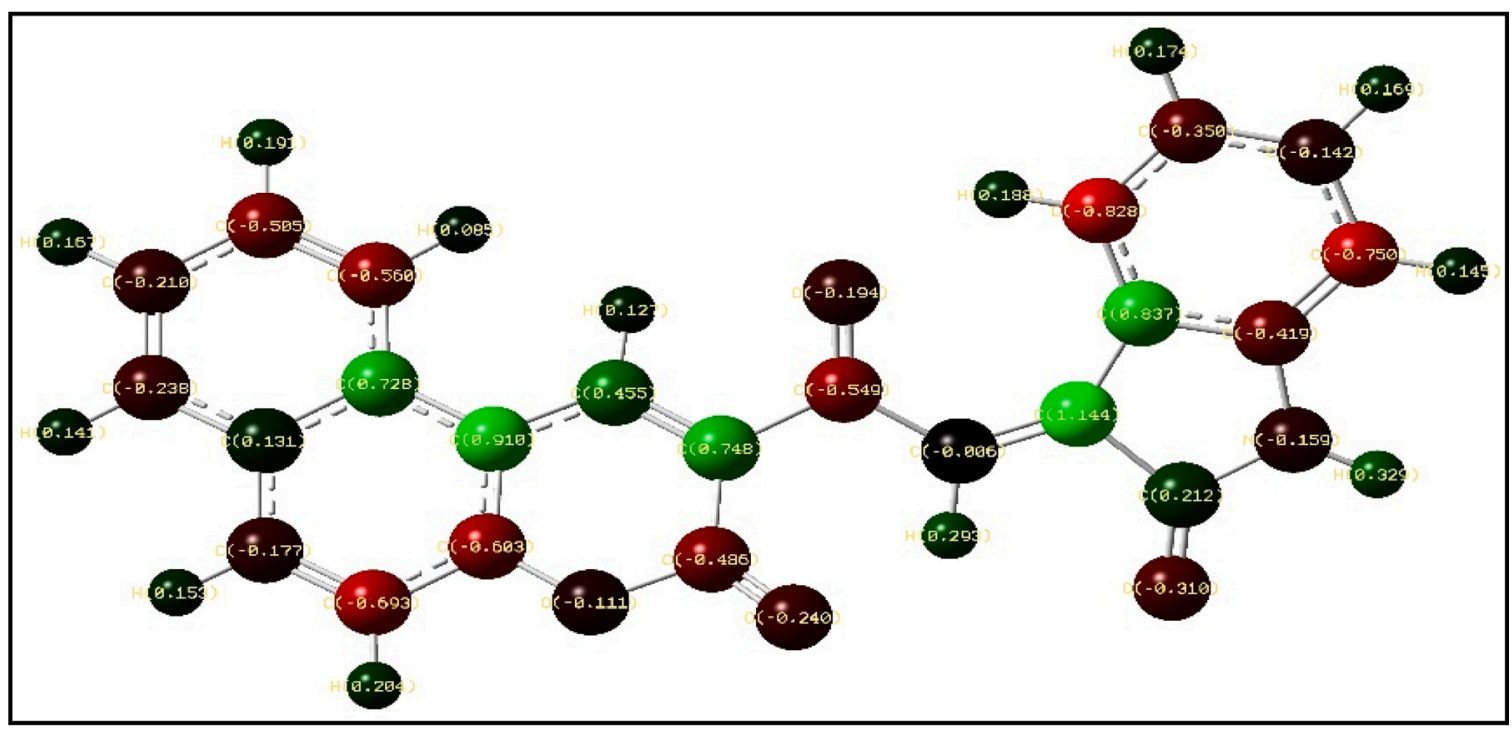

(b) 3OBC

Fig. 14. Mulliken charges for 14 (a) $30 \mathrm{OCE}$ and 14 (b) $3 \mathrm{OBC}$. 
Table 7

(a) Calculated Mulliken atomic charge distribution of 3OCE.

\begin{tabular}{|c|c|c|c|}
\hline \multirow{2}{*}{ Atoms } & \multicolumn{3}{|c|}{ Mulliken atomic charge distribution } \\
\hline & Anion $\mathrm{q}(\mathrm{N}-1)$ & Neutral q(N) & Cation $\mathrm{q}(\mathrm{N}+1)$ \\
\hline $\mathrm{C} 1$ & 0.0294 & 0.0711 & 0.0961 \\
\hline $\mathrm{C} 2$ & -0.1769 & -0.1681 & -0.1465 \\
\hline $\mathrm{C} 3$ & -0.3983 & -0.3620 & -0.3501 \\
\hline $\mathrm{C} 4$ & -0.3760 & -0.3673 & -0.3577 \\
\hline C5 & -1.9284 & -1.9324 & -1.9422 \\
\hline C6 & 1.6064 & 1.5913 & 1.6085 \\
\hline $\mathrm{C} 7$ & 0.3565 & 0.4139 & 0.4314 \\
\hline C8 & 0.4281 & 0.4740 & 0.4954 \\
\hline C9 & -0.2097 & -0.2423 & -0.2450 \\
\hline $\mathrm{O} 10$ & -0.1217 & -0.0893 & -0.0603 \\
\hline H11 & 0.1743 & 0.2094 & 0.2349 \\
\hline H12 & 0.1347 & 0.1789 & 0.2133 \\
\hline H13 & 0.1364 & 0.1760 & 0.2094 \\
\hline H14 & 0.1228 & 0.1515 & 0.1722 \\
\hline H15 & 0.1827 & 0.2127 & 0.2298 \\
\hline 016 & -0.2823 & -0.2443 & -0.2156 \\
\hline O17 & -0.2932 & -0.1973 & -0.1709 \\
\hline C18 & -0.4105 & -0.3696 & -0.3780 \\
\hline C19 & -0.0135 & 0.0098 & 0.0664 \\
\hline C20 & 1.1294 & 1.2504 & 1.3032 \\
\hline $\mathrm{C} 21$ & 0.1840 & 0.2044 & 0.1962 \\
\hline $\mathrm{O} 22$ & -0.3858 & -0.3126 & -0.2105 \\
\hline N23 & -0.1702 & -0.1586 & -0.0942 \\
\hline $\mathrm{C} 24$ & -0.4507 & -0.4817 & -0.4868 \\
\hline $\mathrm{C} 25$ & 0.7331 & 0.7305 & 0.7709 \\
\hline $\mathrm{C} 26$ & -0.7623 & -0.7552 & -0.7520 \\
\hline $\mathrm{C} 27$ & -0.3993 & -0.3668 & -0.2952 \\
\hline $\mathrm{C} 28$ & -0.1714 & -0.1348 & -0.1109 \\
\hline $\mathrm{C} 29$ & -0.7849 & -0.7819 & -0.7669 \\
\hline H30 & 0.1066 & 0.1452 & 0.1971 \\
\hline H31 & 0.1252 & 0.1700 & 0.2289 \\
\hline H32 & 0.1362 & 0.1722 & 0.2340 \\
\hline H33 & 0.1948 & 0.1922 & 0.2197 \\
\hline H34 & 0.2598 & 0.2817 & 0.2996 \\
\hline H35 & 0.2948 & 0.3288 & 0.3758 \\
\hline
\end{tabular}

(b) The calculated Mulliken atomic charge distribution of 3OBC.

\begin{tabular}{|c|c|c|c|}
\hline \multirow{2}{*}{ Atoms } & \multicolumn{3}{|c|}{ Mulliken atomic charge distribution } \\
\hline & Anion $\mathrm{q}(\mathrm{N}-1)$ & Neutral q(N) & Cation $\mathrm{q}(\mathrm{N}+1)$ \\
\hline $\mathrm{C} 1$ & 0.1555 & 0.1314 & 0.1158 \\
\hline $\mathrm{C} 2$ & 0.6997 & 0.7276 & 0.7250 \\
\hline C3 & 0.9015 & 0.9100 & 0.9515 \\
\hline $\mathrm{C} 4$ & -0.6212 & -0.6032 & -0.6001 \\
\hline C5 & -0.6856 & -0.6925 & -0.6912 \\
\hline C6 & -0.2253 & -0.1775 & -0.1454 \\
\hline H7 & 0.1695 & 0.2037 & 0.2337 \\
\hline H8 & 0.1099 & 0.1527 & 0.1890 \\
\hline C9 & 0.3783 & 0.4548 & 0.4732 \\
\hline $\mathrm{C} 10$ & 0.6992 & 0.7482 & 0.7851 \\
\hline C11 & -0.4522 & -0.4860 & -0.4951 \\
\hline $\mathrm{O} 12$ & -0.1450 & -0.1111 & -0.0821 \\
\hline 013 & -0.2778 & -0.2398 & -0.1955 \\
\hline C14 & -0.5688 & -0.5490 & -0.5579 \\
\hline O15 & -0.2838 & -0.1942 & -0.1733 \\
\hline C16 & -0.0271 & -0.0062 & 0.0328 \\
\hline C17 & -0.5486 & -0.5598 & -0.5350 \\
\hline C18 & -0.2594 & -0.2378 & -0.2007 \\
\hline C19 & -0.2159 & -0.2097 & -0.1947 \\
\hline C20 & -0.5252 & -0.5053 & -0.4933 \\
\hline C21 & 1.0317 & 1.1437 & 1.1885 \\
\hline C22 & 0.8424 & 0.8367 & 0.8647 \\
\hline C23 & -0.3938 & -0.4188 & -0.4224 \\
\hline $\mathrm{N} 24$ & -0.1697 & -0.1593 & -0.1128 \\
\hline C25 & 0.1927 & 0.2121 & 0.2103 \\
\hline O26 & -0.3776 & -0.3103 & -0.2319 \\
\hline C27 & -0.8352 & -0.8277 & -0.8264 \\
\hline C28 & -0.7549 & -0.7502 & -0.7371 \\
\hline $\mathrm{C} 29$ & -0.3814 & -0.3505 & -0.2949 \\
\hline C30 & -0.1743 & -0.1421 & -0.1224 \\
\hline H31 & 0.2979 & 0.3293 & 0.3670 \\
\hline H32 & 0.1623 & 0.1913 & 0.2225 \\
\hline H33 & 0.0842 & 0.0850 & 0.1031 \\
\hline
\end{tabular}

Table 7 (continued)

\begin{tabular}{llll}
\hline \multicolumn{4}{l}{ (b) The calculated Mulliken atomic charge distribution of 3OBC. } \\
\hline \multirow{2}{*}{ Atoms } & \multicolumn{2}{l}{ Mulliken atomic charge distribution } \\
\cline { 2 - 4 } & Anion q(N-1) & Neutral q(N) & Cation $\mathrm{q}(\mathrm{N}+1)$ \\
\hline H34 & 0.1341 & 0.1672 & 0.2039 \\
H35 & 0.1125 & 0.1412 & 0.1758 \\
H36 & 0.1078 & 0.1268 & 0.1372 \\
H37 & 0.1919 & 0.1881 & 0.2055 \\
H38 & 0.1410 & 0.1737 & 0.2212 \\
H39 & 0.1277 & 0.1693 & 0.2171 \\
H40 & 0.1093 & 0.1452 & 0.1874 \\
H41 & 0.2740 & 0.2925 & 0.3020 \\
\hline
\end{tabular}

\section{Conclusions}

The results and discussions obtained from the study of 3OCE and 3OBC coumarin compounds infers the following points:

(1) For both the compounds, polar nature in excited state is more as compared to ground state as indicate by large value of dipole moment in excited state.

(2) Observing the Red shift for both 3OCE and 3OBC compounds confirms $\pi \rightarrow \pi^{*}$ and ICT character.

(3) Low energy gap values between HOMO-LUMO signifies high molecular reactivity for both the compounds 3OCE and 3OBC.

(4) The intra-molecular interactions of both compounds are confirmed by NBO analysis.

(5) Electrophilic and nucleophilic reactive sites are predicted in case of both compounds.

(6) The local softness and local electrophilicity indices of 3OCE and 3OBC are determined by Fukui functions.

(7) Molecular docking study revealed that both the coumarin compounds 3OCE and 3OBC showed best suitable binding pattern at the active site by interacting non-covalently with amino acid residues of proteins.

\section{Author contribution statements}

Raveendra Melavanki: Experimental part corrections and manuscript preparation.

Kalpana Sharma: Theoretical part corrections and manuscript preparation.

V. T. Muttannavar: Experimental part did.

Raviraj Kusanur: Involved in experimental work and calculations.

Kariyappa Katagi: Theoretical part did.

Swarna M Patra: Involved in theoretical calculations.

Siva Umapathy: Theoretical part facility providing and guiding for work from lab.

Kishor Kumar Sadasivuni: Molecular docking work carried out.

Vikas M Shelar: Some experimental work did.

Diksha Singh: Some experimental work did.

N R Patil: Some Theoretical part calculations did.

V V Koppal: Some theoretical calculations did.

\section{Declaration of Competing Interest}

This to certify that the article entitled "Quantum chemical computations, Fluorescence spectral features and molecular docking of two biologically active heterocyclic class of compounds" submitted by Raveendra Melavanki etal for the publication in Journal of Photochemistry and Photobiology A: Chemistry is based on the original work and results of the experiments are carried out by all authors under my supervision. No part of the article has been previously submitted for the publication in any journals. 
Table 8

(a) The calculated Fukui functions, local softness and local eletrophilicity indices of 3OCE.

\begin{tabular}{|c|c|c|c|c|c|c|c|c|c|}
\hline Atoms & $f_{k}^{+}$ & $f_{k}^{-}$ & $f_{k}^{0}$ & $S_{k}^{+}$ & $S_{k}^{-}$ & $S_{k}^{0}$ & $\omega_{k}^{+}$ & $\omega_{k}^{-}$ & $\omega_{k}^{0}$ \\
\hline C1 & 0.0250 & 0.0417 & 0.0334 & 0.0167 & 0.0279 & 0.0223 & 0.1952 & 0.3260 & 0.2606 \\
\hline C2 & 0.0216 & 0.0089 & 0.0152 & 0.0144 & 0.0059 & 0.0102 & 0.1685 & 0.0692 & 0.1188 \\
\hline C3 & 0.0119 & 0.0363 & 0.0241 & 0.0079 & 0.0242 & 0.0161 & 0.0926 & 0.2834 & 0.1880 \\
\hline $\mathrm{C} 4$ & 0.0096 & 0.0087 & 0.0092 & 0.0064 & 0.0058 & 0.0061 & 0.0752 & 0.0683 & 0.0717 \\
\hline C5 & -0.0098 & -0.0040 & -0.0069 & -0.0065 & -0.0027 & -0.0046 & -0.0765 & -0.0312 & -0.0538 \\
\hline C6 & 0.0172 & -0.0150 & 0.0011 & 0.0115 & -0.0101 & 0.0007 & 0.1342 & -0.1175 & 0.0083 \\
\hline C7 & 0.0175 & 0.0574 & 0.0375 & 0.0117 & 0.0383 & 0.0250 & 0.1370 & 0.4482 & 0.2926 \\
\hline C8 & 0.0214 & 0.0459 & 0.0336 & 0.0143 & 0.0307 & 0.0225 & 0.1670 & 0.3587 & 0.2628 \\
\hline C9 & -0.0027 & -0.0326 & -0.0176 & -0.0018 & -0.0218 & -0.0118 & -0.0208 & -0.2545 & -0.1376 \\
\hline $\mathrm{O} 10$ & 0.0290 & 0.0324 & 0.0307 & 0.0194 & 0.0217 & 0.0205 & 0.2267 & 0.2532 & 0.2400 \\
\hline H11 & 0.0255 & 0.0350 & 0.0303 & 0.0170 & 0.0234 & 0.0202 & 0.1992 & 0.2736 & 0.2364 \\
\hline $\mathrm{H} 12$ & 0.0344 & 0.0442 & 0.0393 & 0.0230 & 0.0295 & 0.0263 & 0.2688 & 0.3455 & 0.3072 \\
\hline $\mathrm{H} 13$ & 0.0334 & 0.0396 & 0.0365 & 0.0223 & 0.0264 & 0.0244 & 0.2605 & 0.3091 & 0.2848 \\
\hline H14 & 0.0207 & 0.0287 & 0.0247 & 0.0138 & 0.0192 & 0.0165 & 0.1617 & 0.2244 & 0.1930 \\
\hline H15 & 0.0171 & 0.0300 & 0.0235 & 0.0114 & 0.0200 & 0.0157 & 0.1335 & 0.2341 & 0.1838 \\
\hline 016 & 0.0287 & 0.0380 & 0.0334 & 0.0191 & 0.0254 & 0.0223 & 0.2239 & 0.2971 & 0.2605 \\
\hline O17 & 0.0264 & 0.0959 & 0.0612 & 0.0176 & 0.0641 & 0.0409 & 0.2060 & 0.7494 & 0.4777 \\
\hline C18 & -0.0084 & 0.0409 & 0.0163 & -0.0056 & 0.0273 & 0.0109 & -0.0654 & 0.3193 & 0.1270 \\
\hline C19 & 0.0566 & 0.0233 & 0.0399 & 0.0378 & 0.0156 & 0.0267 & 0.4418 & 0.1819 & 0.3119 \\
\hline $\mathrm{C} 20$ & 0.0529 & 0.1210 & 0.0869 & 0.0353 & 0.0808 & 0.0581 & 0.4129 & 0.9452 & 0.6790 \\
\hline $\mathrm{C} 21$ & -0.0082 & 0.0204 & 0.0061 & -0.0055 & 0.0136 & 0.0041 & -0.0642 & 0.1594 & 0.0476 \\
\hline $\mathrm{O} 22$ & 0.1021 & 0.0733 & 0.0877 & 0.0682 & 0.0489 & 0.0586 & 0.7973 & 0.5724 & 0.6848 \\
\hline $\mathrm{N} 23$ & 0.0644 & 0.0116 & 0.0380 & 0.0430 & 0.0078 & 0.0254 & 0.5030 & 0.0908 & 0.2969 \\
\hline $\mathrm{C} 24$ & -0.0051 & -0.0310 & -0.0181 & -0.0034 & -0.0207 & -0.0121 & -0.0396 & -0.2425 & -0.1410 \\
\hline C25 & 0.0404 & -0.0026 & 0.0189 & 0.0270 & -0.0018 & 0.0126 & 0.3156 & -0.0206 & 0.1475 \\
\hline C26 & 0.0031 & 0.0071 & 0.0051 & 0.0021 & 0.0048 & 0.0034 & 0.0245 & 0.0558 & 0.0401 \\
\hline $\mathrm{C} 27$ & 0.0717 & 0.0325 & 0.0521 & 0.0479 & 0.0217 & 0.0348 & 0.5598 & 0.2535 & 0.4066 \\
\hline C28 & 0.0239 & 0.0366 & 0.0303 & 0.0159 & 0.0245 & 0.0202 & 0.1865 & 0.2861 & 0.2363 \\
\hline C29 & 0.0149 & 0.0030 & 0.0090 & 0.0100 & 0.0020 & 0.0060 & 0.1166 & 0.0233 & 0.0700 \\
\hline Н30 & 0.0519 & 0.0386 & 0.0452 & 0.0347 & 0.0258 & 0.0302 & 0.4053 & 0.3013 & 0.3533 \\
\hline H31 & 0.0589 & 0.0449 & 0.0519 & 0.0394 & 0.0300 & 0.0347 & 0.4603 & 0.3503 & 0.4053 \\
\hline H32 & 0.0617 & 0.0360 & 0.0489 & 0.0412 & 0.0241 & 0.0327 & 0.4823 & 0.2815 & 0.3819 \\
\hline H33 & 0.0275 & -0.0026 & 0.0124 & 0.0183 & -0.0017 & 0.0083 & 0.2145 & -0.0202 & 0.0972 \\
\hline H34 & 0.0179 & 0.0219 & 0.0199 & 0.0120 & 0.0147 & 0.0133 & 0.1398 & 0.1713 & 0.1556 \\
\hline H35 & 0.0470 & 0.0340 & 0.0405 & 0.0314 & 0.0227 & 0.0270 & 0.3673 & 0.2652 & 0.3162 \\
\hline
\end{tabular}

(b) The calculated Fukui functions, local softness and local eletrophilicity indices of 3OBC.

\begin{tabular}{|c|c|c|c|c|c|c|c|c|c|}
\hline Atoms & $f_{k}^{+}$ & $f_{k}^{-}$ & $f_{k}^{0}$ & $S_{k}^{+}$ & $S_{k}^{-}$ & $S_{k}^{0}$ & $\omega_{k}^{+}$ & $\omega_{k}^{-}$ & $\omega_{k}^{0}$ \\
\hline $\mathrm{C} 1$ & -0.0156 & -0.0241 & -0.0198 & -0.0105 & -0.0162 & -0.0134 & -0.1213 & -0.1870 & -0.1542 \\
\hline $\mathrm{C} 2$ & -0.0026 & 0.0279 & 0.0126 & -0.0018 & 0.0188 & 0.0085 & -0.0204 & 0.2167 & 0.0981 \\
\hline C3 & 0.0414 & 0.0085 & 0.0250 & 0.0279 & 0.0057 & 0.0168 & 0.3221 & 0.0663 & 0.1942 \\
\hline $\mathrm{C} 4$ & 0.0032 & 0.0180 & 0.0106 & 0.0021 & 0.0121 & 0.0071 & 0.0247 & 0.1399 & 0.0823 \\
\hline C5 & 0.0013 & -0.0069 & -0.0028 & 0.0009 & -0.0047 & -0.0019 & 0.0104 & -0.0539 & -0.0217 \\
\hline C6 & 0.0321 & 0.0478 & 0.0399 & 0.0216 & 0.0322 & 0.0269 & 0.2495 & 0.3717 & 0.3106 \\
\hline $\mathrm{H} 7$ & 0.0300 & 0.0342 & 0.0321 & 0.0202 & 0.0231 & 0.0216 & 0.2332 & 0.2660 & 0.2496 \\
\hline H8 & 0.0363 & 0.0429 & 0.0396 & 0.0245 & 0.0289 & 0.0267 & 0.2824 & 0.3334 & 0.3079 \\
\hline C9 & 0.0184 & 0.0765 & 0.0475 & 0.0124 & 0.0516 & 0.0320 & 0.1432 & 0.5948 & 0.3690 \\
\hline C10 & 0.0368 & 0.0491 & 0.0429 & 0.0248 & 0.0331 & 0.0289 & 0.2864 & 0.3815 & 0.3339 \\
\hline C11 & -0.0092 & -0.0338 & -0.0215 & -0.0062 & -0.0228 & -0.0145 & -0.0712 & -0.2626 & -0.1669 \\
\hline $\mathrm{O} 12$ & 0.0290 & 0.0340 & 0.0315 & 0.0195 & 0.0229 & 0.0212 & 0.2255 & 0.2641 & 0.2448 \\
\hline 013 & 0.0443 & 0.0380 & 0.0412 & 0.0298 & 0.0256 & 0.0277 & 0.3442 & 0.2959 & 0.3201 \\
\hline C14 & -0.0090 & 0.0198 & 0.0054 & -0.0061 & 0.0134 & 0.0037 & -0.0698 & 0.1543 & 0.0423 \\
\hline O15 & 0.0210 & 0.0896 & 0.0553 & 0.0141 & 0.0604 & 0.0373 & 0.1629 & 0.6971 & 0.4300 \\
\hline C16 & 0.0390 & 0.0209 & 0.0299 & 0.0263 & 0.0141 & 0.0202 & 0.3029 & 0.1626 & 0.2328 \\
\hline C17 & 0.0248 & -0.0111 & 0.0068 & 0.0167 & -0.0075 & 0.0046 & 0.1929 & -0.0866 & 0.0531 \\
\hline C18 & 0.0371 & 0.0216 & 0.0293 & 0.0250 & 0.0145 & 0.0198 & 0.2884 & 0.1677 & 0.2281 \\
\hline C19 & 0.0149 & 0.0062 & 0.0106 & 0.0101 & 0.0042 & 0.0071 & 0.1162 & 0.0482 & 0.0822 \\
\hline $\mathrm{C} 20$ & 0.0120 & 0.0199 & 0.0159 & 0.0081 & 0.0134 & 0.0107 & 0.0933 & 0.1546 & 0.1239 \\
\hline $\mathrm{C} 21$ & 0.0448 & 0.1121 & 0.0784 & 0.0302 & 0.0755 & 0.0529 & 0.3485 & 0.8714 & 0.6099 \\
\hline $\mathrm{C} 22$ & 0.0279 & -0.0057 & 0.0111 & 0.0188 & -0.0038 & 0.0075 & 0.2171 & -0.0440 & 0.0866 \\
\hline $\mathrm{C} 23$ & -0.0036 & -0.0249 & -0.0143 & -0.0025 & -0.0168 & -0.0096 & -0.0283 & -0.1937 & -0.1110 \\
\hline $\mathrm{N} 24$ & 0.0465 & 0.0105 & 0.0285 & 0.0313 & 0.0070 & 0.0192 & 0.3613 & 0.0813 & 0.2213 \\
\hline $\mathrm{C} 25$ & -0.0019 & 0.0194 & 0.0088 & -0.0013 & 0.0131 & 0.0059 & -0.0145 & 0.1512 & 0.0683 \\
\hline $\mathrm{O} 26$ & 0.0784 & 0.0673 & 0.0728 & 0.0528 & 0.0453 & 0.0491 & 0.6097 & 0.5230 & 0.5663 \\
\hline $\mathrm{C} 27$ & 0.0013 & 0.0076 & 0.0044 & 0.0008 & 0.0051 & 0.0030 & 0.0098 & 0.0588 & 0.0343 \\
\hline $\mathrm{C} 28$ & 0.0130 & 0.0047 & 0.0089 & 0.0088 & 0.0032 & 0.0060 & 0.1011 & 0.0368 & 0.0690 \\
\hline $\mathrm{C} 29$ & 0.0556 & 0.0309 & 0.0432 & 0.0375 & 0.0208 & 0.0291 & 0.4323 & 0.2400 & 0.3362 \\
\hline C30 & 0.0197 & 0.0322 & 0.0260 & 0.0133 & 0.0217 & 0.0175 & 0.1532 & 0.2505 & 0.2019 \\
\hline H31 & 0.0377 & 0.0314 & 0.0346 & 0.0254 & 0.0212 & 0.0233 & 0.2931 & 0.2444 & 0.2688 \\
\hline H32 & 0.0312 & 0.0290 & 0.0301 & 0.0210 & 0.0195 & 0.0203 & 0.2428 & 0.2252 & 0.2340 \\
\hline H33 & 0.0181 & 0.0008 & 0.0095 & 0.0122 & 0.0006 & 0.0064 & 0.1410 & 0.0066 & 0.0738 \\
\hline H34 & 0.0367 & 0.0331 & 0.0349 & 0.0247 & 0.0223 & 0.0235 & 0.2853 & 0.2577 & 0.2715 \\
\hline H35 & 0.0345 & 0.0288 & 0.0317 & 0.0233 & 0.0194 & 0.0213 & 0.2686 & 0.2237 & 0.2461 \\
\hline
\end{tabular}


Table 8 (continued)

(b) The calculated Fukui functions, local softness and local eletrophilicity indices of 3OBC.

\begin{tabular}{|c|c|c|c|c|c|c|c|c|c|}
\hline Atoms & $f_{k}^{+}$ & $f_{k}^{-}$ & $f_{k}^{0}$ & $S_{k}^{+}$ & $S_{k}^{-}$ & $S_{k}^{0}$ & $\omega_{k}^{+}$ & $\omega_{k}^{-}$ & $\omega_{k}^{0}$ \\
\hline H36 & 0.0105 & 0.0190 & 0.0147 & 0.0071 & 0.0128 & 0.0099 & 0.0815 & 0.1477 & 0.1146 \\
\hline H37 & 0.0173 & -0.0038 & 0.0068 & 0.0117 & -0.0026 & 0.0046 & 0.1348 & -0.0295 & 0.0526 \\
\hline H38 & 0.0476 & 0.0327 & 0.0401 & 0.0320 & 0.0220 & 0.0270 & 0.3697 & 0.2539 & 0.3118 \\
\hline H39 & 0.0479 & 0.0416 & 0.0447 & 0.0323 & 0.0280 & 0.0301 & 0.3721 & 0.3231 & 0.3476 \\
\hline $\mathrm{H} 40$ & 0.0422 & 0.0359 & 0.0391 & 0.0284 & 0.0242 & 0.0263 & 0.3281 & 0.2794 & 0.3037 \\
\hline H41 & 0.0094 & 0.0185 & 0.0140 & 0.0064 & 0.0125 & 0.0094 & 0.0734 & 0.1439 & 0.1087 \\
\hline
\end{tabular}

Table 9

(a) Second order perturbation theory analysis of Fock matrix in NBO basis of 3OCE.

\begin{tabular}{|c|c|c|c|c|c|c|c|c|}
\hline Donor(I) & Type of Band & Occupancy & Acceptor(J) & Type of Band & Occupancy & $\mathrm{E} 2(\mathrm{Kj} / \mathrm{mol})^{\mathrm{a}}$ & $E(j)-E(i)(a . u)^{b}$ & $F(i, j)(a . u)^{c}$ \\
\hline $\mathrm{C} 1-\mathrm{C} 2$ & $\pi$ & 1.69733 & C3-C4 & $\pi^{*}$ & 0.30208 & 22.41 & 0.27 & 0.07 \\
\hline $\mathrm{C} 1-\mathrm{C} 2$ & $\pi$ & 1.69733 & C5-C6 & $\pi^{*}$ & 0.43606 & 19.34 & 0.24 & 0.063 \\
\hline \multirow[t]{2}{*}{ C3-C4 } & $\pi$ & 1.67783 & $\mathrm{C} 1-\mathrm{C} 2$ & $\pi^{*}$ & 0.28548 & 15.95 & 0.29 & 0.061 \\
\hline & $\pi$ & 1.67783 & C5-C6 & $\pi^{*}$ & 0.02149 & 22.26 & 0.24 & 0.068 \\
\hline \multirow[t]{3}{*}{ C5-C6 } & $\pi$ & 1.57918 & $\mathrm{C} 1-\mathrm{C} 2$ & $\pi^{*}$ & 0.28548 & 18.96 & 0.29 & 0.069 \\
\hline & $\pi$ & 1.57918 & C3-C4 & $\pi^{*}$ & 0.30208 & 16.12 & 0.28 & 0.062 \\
\hline & $\pi$ & 1.57918 & C7-C8 & $\pi^{*}$ & 0.17173 & 24.74 & 0.21 & 0.07 \\
\hline \multirow[t]{3}{*}{ C7-C8 } & $\pi$ & 1.76238 & C5-C6 & $\pi^{*}$ & 0.43606 & 12.51 & 0.26 & 0.054 \\
\hline & $\pi$ & 1.76238 & C9-O16 & $\pi^{*}$ & 0.27556 & 24.43 & 0.3 & 0.077 \\
\hline & $\pi$ & 1.76238 & O17-C18 & $\pi^{*}$ & 0.21478 & 20.53 & 0.24 & 0.064 \\
\hline C7-H15 & $\sigma$ & 1.97756 & C8-C9 & $\sigma^{*}$ & 0.06404 & 12.61 & 0.43 & 0.067 \\
\hline C18-C19 & $\sigma$ & 1.97936 & C27-C28 & $\sigma^{*}$ & 0.01569 & 10.03 & 0.33 & 0.051 \\
\hline \multirow[t]{3}{*}{ C19-C20 } & $\pi$ & 1.77557 & O17-C18 & $\pi^{*}$ & 0.21478 & 25.14 & 0.23 & 0.068 \\
\hline & $\pi$ & 1.77557 & $\mathrm{C} 21-\mathrm{O} 22$ & $\pi^{*}$ & 0.26996 & 17.58 & 0.27 & 0.062 \\
\hline & $\pi$ & 1.77557 & C25-C26 & $\pi^{*}$ & 0.36714 & 11.92 & 0.31 & 0.056 \\
\hline \multirow[t]{2}{*}{$\mathrm{C} 20-\mathrm{C} 21$} & $\sigma$ & 1.96426 & C8-C9 & $\sigma^{*}$ & 0.06404 & 27.11 & 0.5 & 0.105 \\
\hline & $\sigma$ & 1.96426 & C25-C26 & $\sigma^{*}$ & 0.02407 & 10.14 & 1.15 & 0.097 \\
\hline C20-C25 & $\sigma$ & 1.96986 & C8-C9 & $\sigma^{*}$ & 0.06404 & 15.19 & 0.56 & 0.083 \\
\hline \multirow[t]{2}{*}{$\mathrm{C} 21-\mathrm{O} 22$} & $\sigma$ & 1.99468 & C7-H15 & $\sigma^{*}$ & 0.01701 & 12.04 & 1.36 & 0.115 \\
\hline & $\sigma$ & 1.99468 & C8-C9 & $\sigma^{*}$ & 0.06404 & 62.42 & 0.97 & 0.223 \\
\hline \multirow[t]{6}{*}{ C21-N23 } & $\sigma$ & 1.98775 & C4-C5 & $\sigma^{*}$ & 0.02149 & 79.72 & 1.17 & 0.274 \\
\hline & $\sigma$ & 1.98775 & C7-H15 & $\sigma^{*}$ & 0.01701 & 50.5 & 1.14 & 0.214 \\
\hline & $\sigma$ & 1.98775 & C8-C9 & $\sigma^{*}$ & 0.06404 & 288.47 & 0.75 & 0.419 \\
\hline & $\sigma$ & 1.98775 & C18-C19 & $\sigma^{*}$ & 0.05302 & 51.79 & 1.15 & 0.22 \\
\hline & $\sigma$ & 1.98775 & C27-C28 & $\sigma^{*}$ & 0.01569 & 395.09 & 0.5 & 0.398 \\
\hline & $\sigma$ & 1.98775 & C29-H30 & $\sigma^{*}$ & 0.01374 & 30.45 & 2.54 & 0.249 \\
\hline \multirow[t]{6}{*}{ N23-C24 } & $\sigma$ & 1.98561 & C4-C5 & $\sigma^{*}$ & 0.02149 & 86.6 & 1.21 & 0.29 \\
\hline & $\sigma$ & 1.98561 & C7-H15 & $\sigma^{*}$ & 0.01701 & 56.57 & 1.17 & 0.23 \\
\hline & $\sigma$ & 1.98561 & C8-C9 & $\sigma^{*}$ & 0.06404 & 311.66 & 0.78 & 0.446 \\
\hline & $\sigma$ & 1.98561 & C18-C19 & $\sigma^{*}$ & 0.05302 & 56.6 & 1.18 & 0.233 \\
\hline & $\sigma$ & 1.98561 & C27-C28 & $\sigma^{*}$ & 0.01569 & 446.7 & 0.54 & 0.438 \\
\hline & $\sigma$ & 1.98561 & C29-H30 & $\sigma^{*}$ & 0.01374 & 50.67 & 2.58 & 0.323 \\
\hline \multirow[t]{6}{*}{ N23-H35 } & $\sigma$ & 1.98845 & C1-H14 & $\sigma^{*}$ & 0.01336 & 23.48 & 0.56 & 0.102 \\
\hline & $\sigma$ & 1.98845 & C4-C5 & $\sigma^{*}$ & 0.02149 & 33.34 & 0.5 & 0.115 \\
\hline & $\sigma$ & 1.98845 & C7-H15 & $\sigma^{*}$ & 0.01701 & 24.48 & 0.46 & 0.095 \\
\hline & $\sigma$ & 1.98845 & C8-C9 & $\sigma^{*}$ & 0.06404 & 606.52 & 0.07 & 0.186 \\
\hline & $\sigma$ & 1.98845 & C18-C19 & $\sigma^{*}$ & 0.05302 & 32.21 & 0.47 & 0.111 \\
\hline & $\sigma$ & 1.98845 & C29-H30 & $\sigma^{*}$ & 0.01374 & 43.41 & 1.87 & 0.254 \\
\hline C24-C25 & $\sigma$ & 1.96108 & C8-C9 & $\sigma^{*}$ & 0.06404 & 35.76 & 0.57 & 0.128 \\
\hline \multirow[t]{6}{*}{ C24-C29 } & $\sigma$ & 1.97605 & C4-C5 & $\sigma^{*}$ & 0.02149 & 22.27 & 1.05 & 0.137 \\
\hline & $\sigma$ & 1.97605 & C7-C8 & $\sigma^{*}$ & 0.17173 & 10.01 & 0.67 & 0.076 \\
\hline & $\sigma$ & 1.97605 & C7-H15 & $\sigma^{*}$ & 0.01701 & 14.49 & 1.01 & 0.108 \\
\hline & $\sigma$ & 1.97605 & C8-C9 & $\sigma^{*}$ & 0.06404 & 87.53 & 0.62 & 0.21 \\
\hline & $\sigma$ & 1.97605 & C18-C19 & $\sigma^{*}$ & 0.05302 & 12.71 & 1.02 & 0.103 \\
\hline & $\sigma$ & 1.97605 & C27-C28 & $\sigma^{*}$ & 0.01569 & 30.02 & 0.38 & 0.095 \\
\hline C24-C29 & $\pi$ & 1.66746 & C25-C26 & $\pi^{*}$ & 0.36714 & 14.84 & 0.3 & 0.06 \\
\hline \multirow[t]{2}{*}{ C25-C26 } & $\pi$ & 1.62799 & C19-C20 & $\pi^{*}$ & 0.14243 & 17.32 & 0.29 & 0.067 \\
\hline & $\pi$ & 1.62799 & C24-C29 & $\pi^{*}$ & 0.36651 & 24.24 & 0.27 & 0.073 \\
\hline C26-C27 & $\sigma$ & 1.97623 & C27-C28 & $\sigma^{*}$ & 0.01569 & 11.6 & 0.34 & 0.056 \\
\hline C26-H33 & $\sigma$ & 1.97768 & C27-C28 & $\sigma^{*}$ & 0.01569 & 19.03 & 0.16 & 0.049 \\
\hline \multirow[t]{2}{*}{ C27-C28 } & $\pi$ & 1.66258 & C24-C29 & $\pi^{*}$ & 0.36651 & 16.4 & 0.28 & 0.06 \\
\hline & $\pi$ & 1.66258 & C25-C26 & $\pi^{*}$ & 0.36714 & 23.45 & 0.28 & 0.073 \\
\hline \multirow[t]{4}{*}{ C28-H31 } & $\sigma$ & 1.98053 & C8-C9 & $\sigma^{*}$ & 0.06404 & 21.02 & 0.43 & 0.085 \\
\hline & $\sigma$ & 1.98053 & C27-C28 & $\sigma^{*}$ & 0.01569 & 91.52 & 0.18 & 0.116 \\
\hline & $\sigma$ & 1.97911 & C8-C9 & $\sigma^{*}$ & 0.06404 & 38.34 & 0.42 & 0.115 \\
\hline & $\sigma$ & 1.97911 & C27-C28 & $\sigma^{*}$ & 0.01569 & 53.02 & 0.18 & 0.087 \\
\hline \multirow[t]{3}{*}{ C5-C6 } & $\pi$ & 0.43606 & $\mathrm{C} 1-\mathrm{C} 2$ & $\pi^{*}$ & 0.28548 & 74.76 & 0.04 & 0.085 \\
\hline & $\pi$ & 0.43606 & C3-C4 & $\pi^{*}$ & 0.01336 & 62.02 & 0.03 & 0.06 \\
\hline & $\pi$ & 0.43606 & $\mathrm{C} 21-\mathrm{O} 22$ & $\pi^{*}$ & 0.26996 & 14.87 & 0.02 & 0.026 \\
\hline C7-C8 & $\pi$ & 0.17173 & C5-C6 & $\pi^{*}$ & 0.43606 & 162.88 & 0.04 & 0.123 \\
\hline
\end{tabular}


Table 9 (continued)

\begin{tabular}{|c|c|c|c|c|c|c|c|c|}
\hline Donor(I) & Type of Band & Occupancy & Acceptor(J) & Type of Band & Occupancy & $\mathrm{E} 2(\mathrm{Kj} / \mathrm{mol})^{\mathrm{a}}$ & $E(j)-E(i)(a \cdot u)^{b}$ & $F(i, j)(a . u)^{c}$ \\
\hline & $\pi$ & 0.17173 & C9-O16 & $\pi^{*}$ & 0.27556 & 21.69 & 0.07 & 0.073 \\
\hline & $\pi$ & 0.17173 & C21-O22 & $\pi^{*}$ & 0.26996 & 10.43 & 0.06 & 0.046 \\
\hline C9-O10 & $\sigma$ & 0.1243 & C5-O10 & $\sigma^{*}$ & 0.03292 & 11.92 & 0.05 & 0.077 \\
\hline \multirow[t]{3}{*}{ O17-C18 } & $\pi$ & 0.21478 & C5-C6 & $\pi^{*}$ & 0.43606 & 29.01 & 0.02 & 0.036 \\
\hline & $\pi$ & 0.21478 & C19-C20 & $\pi^{*}$ & 0.14243 & 16.25 & 0.09 & 0.08 \\
\hline & $\pi$ & 0.21478 & C21-O22 & $\pi^{*}$ & 0.26996 & 11.22 & 0.04 & 0.038 \\
\hline $\mathrm{C} 21-\mathrm{O} 22$ & $\pi$ & 0.26996 & C19-C20 & $\pi^{*}$ & 0.14243 & 23.89 & 0.05 & 0.067 \\
\hline \multicolumn{9}{|c|}{ (b) Second order perturbation theory analysis of Fock matrix in NBO basis of $3 \mathrm{OBC}$. } \\
\hline Donor(I) & Type of Band & Occupancy & Acceptor(J) & Type of Band & Occupancy & $\mathrm{E} 2(\mathrm{Kj} / \mathrm{mol})^{\mathrm{a}}$ & $E(j)-E(i)(a . u)^{b}$ & $F(i, j)(a . u)^{c}$ \\
\hline $\mathrm{O} 12$ & $\mathrm{LP}(2)$ & 1.766 & C3-C4 & $\pi^{*}$ & 0.411 & 32.42 & 0.33 & 0.096 \\
\hline $\mathrm{O} 12$ & $\mathrm{LP}(2)$ & 1.766 & $\mathrm{C} 11-013$ & $\pi^{*}$ & 0.252 & 34.12 & 0.31 & 0.093 \\
\hline $\mathrm{O} 13$ & $\mathrm{LP}(2)$ & 1.844 & $\mathrm{C} 11-\mathrm{O} 12$ & $\sigma^{*}$ & 0.118 & 41.51 & 0.49 & 0.128 \\
\hline $\mathrm{O} 15$ & $\mathrm{LP}(2)$ & 1.879 & C10-C14 & $\sigma^{*}$ & 0.066 & 17.52 & 0.68 & 0.098 \\
\hline N24 & $\mathrm{LP}(1)$ & 1.773 & C23-C28 & $\pi^{*}$ & 0.087 & 38.71 & 0.29 & 0.095 \\
\hline N24 & $\mathrm{LP}(1)$ & 1.773 & C25-O26 & $\pi^{*}$ & 0.015 & 60.21 & 0.26 & 0.112 \\
\hline \multirow[t]{4}{*}{ C1-C2 } & $\pi$ & 1.587 & C3-C4 & $\pi^{*}$ & 0.411 & 16.68 & 0.25 & 0.059 \\
\hline & $\pi$ & 1.587 & C5-C6 & $\pi^{*}$ & 0.292 & 17.64 & 0.27 & 0.065 \\
\hline & $\pi$ & 1.587 & C17-C20 & $\pi^{*}$ & 0.147 & 16.46 & 0.27 & 0.063 \\
\hline & $\pi$ & 1.587 & C18-C19 & $\pi^{*}$ & 0.144 & 17.18 & 0.28 & 0.065 \\
\hline \multirow[t]{3}{*}{ C3-C4 } & $\pi$ & 1.646 & $\mathrm{C} 1-\mathrm{C} 2$ & $\pi^{*}$ & 0.400 & 16.92 & 0.29 & 0.064 \\
\hline & $\pi$ & 1.646 & C5-C6 & $\pi^{*}$ & 0.292 & 13.31 & 0.3 & 0.058 \\
\hline & $\pi$ & 1.646 & C9-C10 & $\pi^{*}$ & 0.135 & 21.11 & 0.29 & 0.073 \\
\hline \multirow[t]{2}{*}{ C5-C6 } & $\pi$ & 1.685 & $\mathrm{C} 1-\mathrm{C} 2$ & $\pi^{*}$ & 0.400 & 14.2 & 0.29 & 0.06 \\
\hline & $\pi$ & 1.685 & C3-C4 & $\pi^{*}$ & 0.411 & 21.32 & 0.28 & 0.071 \\
\hline \multirow[t]{3}{*}{ C9-C10 } & $\pi$ & 1.789 & C3-C4 & $\pi^{*}$ & 0.411 & 12.08 & 0.28 & 0.054 \\
\hline & $\pi$ & 1.789 & C11-O13 & $\pi^{*}$ & 0.252 & 30.7 & 0.26 & 0.08 \\
\hline & $\pi$ & 1.789 & C14-O15 & $\pi^{*}$ & 0.281 & 22.9 & 0.27 & 0.07 \\
\hline C9-H36 & $\sigma$ & 1.979 & C10-C11 & $\sigma^{*}$ & 0.066 & 5.52 & 0.99 & 0.067 \\
\hline C11-O13 & $\pi$ & 1.981 & C9-C10 & $\pi^{*}$ & 0.135 & 5.52 & 0.39 & 0.043 \\
\hline C14-O15 & $\pi$ & 1.965 & C16-C21 & $\pi^{*}$ & 0.150 & 6 & 0.4 & 0.045 \\
\hline C16-C21 & $\sigma$ & 1.981 & C21-C22 & $\sigma^{*}$ & 0.033 & 5.53 & 1.23 & 0.074 \\
\hline \multirow[t]{3}{*}{ C16-C21 } & $\pi$ & 1.759 & C14-O15 & $\pi^{*}$ & 0.281 & 24.3 & 0.25 & 0.07 \\
\hline & $\pi$ & 1.759 & C22-C27 & $\pi^{*}$ & 0.028 & 12.05 & 0.3 & 0.056 \\
\hline & $\pi$ & 1.759 & C25-O26 & $\pi^{*}$ & 0.015 & 18.8 & 0.26 & 0.063 \\
\hline C16-H41 & $\sigma$ & 1.975 & C21-C22 & $\sigma^{*}$ & 0.033 & 8.62 & 1 & 0.083 \\
\hline \multirow[t]{2}{*}{$\mathrm{C} 17-\mathrm{C} 20$} & $\pi$ & 1.840 & $\mathrm{C} 1-\mathrm{C} 2$ & $\pi^{*}$ & 0.400 & 18.61 & 0.28 & 0.067 \\
\hline & $\pi$ & 1.840 & C18-C19 & $\pi^{*}$ & 0.144 & 17.4 & 0.29 & 0.063 \\
\hline \multirow[t]{2}{*}{ C18-C19 } & $\pi$ & 1.841 & $\mathrm{C} 1-\mathrm{C} 2$ & $\pi^{*}$ & 0.400 & 17.16 & 0.28 & 0.064 \\
\hline & $\pi$ & 1.841 & C17-C20 & $\pi^{*}$ & 0.147 & 18.87 & 0.28 & 0.066 \\
\hline \multirow[t]{3}{*}{ C22-C27 } & $\pi$ & 1.970 & C16-C21 & $\pi^{*}$ & 0.150 & 17.63 & 0.28 & 0.066 \\
\hline & $\pi$ & 1.970 & C23-C28 & $\pi^{*}$ & 0.087 & 24.05 & 0.26 & 0.071 \\
\hline & $\pi$ & 1.970 & C29-C30 & $\pi^{*}$ & 0.029 & 16.83 & 0.27 & 0.061 \\
\hline \multirow[t]{2}{*}{ C23-C28 } & $\pi$ & 1.987 & C22-C27 & $\pi^{*}$ & 0.028 & 14.6 & 0.3 & 0.059 \\
\hline & $\pi$ & 1.987 & C29-C30 & $\pi^{*}$ & 0.029 & 21.92 & 0.29 & 0.071 \\
\hline C27-C29 & $\sigma$ & 1.768 & C21-C22 & $\sigma^{*}$ & 0.033 & 5.02 & 1.17 & 0.069 \\
\hline C28-C30 & $\sigma$ & 1.983 & C23-N24 & $\sigma^{*}$ & 0.025 & 6.14 & 1.1 & 0.073 \\
\hline \multirow[t]{2}{*}{ C29-C30 } & $\pi$ & 1.982 & C22-C27 & $\pi^{*}$ & 0.028 & 23.15 & 0.28 & 0.072 \\
\hline & $\pi$ & 1.982 & C23-C28 & $\pi^{*}$ & 0.087 & 16.93 & 0.27 & 0.061 \\
\hline
\end{tabular}

${ }^{\text {a }}$ E2 means energy of hyper conjugative interactions.

b Energy difference between donor adn acceptor i. and j. NBO orbitals.

${ }^{c} \mathrm{~F}(\mathrm{i}, \mathrm{j})$ is the Fock matrix element between i. and j. NBO orbitals. 
Table 10

Interaction of 2IPM and 2IPL protein for both compounds 3OCE and 3OBC with docked energy.

\begin{tabular}{|c|c|c|c|c|}
\hline \multirow{2}{*}{$\begin{array}{l}\text { Docked energy } \\
\text { parameters }\end{array}$} & \multicolumn{2}{|l|}{ PDB-2IPM } & \multicolumn{2}{|c|}{ PDB-2IPL } \\
\hline & 3OCE & 3OBC & 3OCE & 3ОВС \\
\hline $\begin{array}{l}\text { Binding_Energy (kcal/ } \\
\text { mol) }\end{array}$ & -8.85 & -10.11 & -8.22 & -9.34 \\
\hline Ligand_Efficiency & -0.37 & -0.36 & -0.34 & -0.33 \\
\hline Inhib_Constant & $\begin{array}{l}323.93 \\
(\mathrm{nM})\end{array}$ & $\begin{array}{l}38.61 \\
(\mathrm{nM})\end{array}$ & $\begin{array}{l}950.59 \\
(\mathrm{nM})\end{array}$ & $142.22(\mathrm{nM})$ \\
\hline $\begin{array}{l}\text { Intermol_Energy (kcal/ } \\
\text { mol) }\end{array}$ & -9.45 & -10.71 & -8.81 & -9.94 \\
\hline $\begin{array}{l}\text { Vdw_hb_desol_energy } \\
\text { (kcal/mol) }\end{array}$ & -9.44 & -10.63 & -8.69 & -9.92 \\
\hline $\begin{array}{l}\text { Electrostatic_energy } \\
(\mathrm{kcal} / \mathrm{mol})\end{array}$ & -0.01 & -0.08 & -0.12 & -0.02 \\
\hline Total_internal & -0.45 & -0.52 & -0.53 & -0.6 \\
\hline Torsional_energy & 0.6 & 0.6 & 0.6 & 0.6 \\
\hline Unbound_energy & -0.45 & -0.52 & -0.53 & -0.6 \\
\hline Hydrogen Bond & $\begin{array}{l}\text { GLN35, } \\
\text { ALA258, } \\
\text { ASN259, } \\
\text { CYS70 }\end{array}$ & $\begin{array}{l}\text { GLN35, } \\
\text { LYS285, }\end{array}$ & $\begin{array}{l}\text { GLN35, } \\
\text { MET38, } \\
\text { LYS22 }\end{array}$ & $\begin{array}{l}\text { MET38, } \\
\text { GLN26, } \\
\text { LEU36, } \\
\text { VAL232, } \\
\text { SER18, } \\
\text { LYS22, } \\
\text { LYS285 }\end{array}$ \\
\hline
\end{tabular}

\section{References}

[1] J.R. Lakowicz, Principle of Fluorescence Spectroscopy, Plenum Press, New York, 1983.

[2] K.K. Rohtagi-Mukherjee, Fundamentals of Photochemistry, Wiley Eastern Ltd., 1992.

[3] A.M. Musa, S.J. Cooper wood, M. Omar, F. Khan, Curr. Med. Chem. 15 (26) (2008) 2664-2679.

[4] Liang Lei, Yong-bo Xue, Zhong Liu, Si-si Peng, Yan He, Yang Zhang, Rong Fang, Jian-ping Wang, Zeng-wei Luo, Guang-min Yao, Jin-wen Zhang, Geng Zhang, Hong-ping Song, Yong-hui Zhang, Sci. Rep. 5 (2015), 13544.

[5] G. Collin, H. Höke, "Quinoline and Isoquinoline", Ullmann's Encyclopedia of Industrial Chemistry, Wiley-VCH, Weinheim, 2005, pp. a22-465.

[6] A. Kawski, B. Kuklinski, P. Bojarski, Chem. Phys. Lett. 448 (2007) 208-212.

[7] G.V. Muddapur, N.R. Patil, S.S. Patil, R.M. Melavanki, R.A. Kusanur, J. Fluoresc. 24 (6) (2014) 1651-1659.

[8] S.S. Patil, G.V. Muddapur, N.R. Patil, R.M. Melavanki, R.A. Kusanur, Spectrochim. Part A Mol. Biomol. Spectrosc. 138 (5) (2015) 85-91.

[9] E. Lippert, Z. Elektrochem. 61 (1957) 962-975.

[10] N.G. Bakshiev, Opt. Spectrosk. 16 (1964) 821-832.

[11] L. Bilot, A. Kawski, Z. Naturforsch. 18A (1963) 10-256. L. Bilot, A. Kawski, Z. Naturforsch., 17A (1962)- 621-627.

[12] A. Chamma, P. Viallet, C.R. Acad, Sci. Paris Ser. C 270 (1970) 1901-1904.

[13] A.R. Katritzky, D.C. Fara, H. Yang, K. Tamm, T. Tamm, M. Karelson, Chem. Rev. 104 (1) (2004) 175-198.

[14] C. Reichardt, Solvents and Solvent Effects in Organic Chemistry, 2 $2^{\text {nd }}$, VCH, 1988.

[15] G.V. Muddapur, V.V. Koppal, N.R. Patil, R.M. Melavanki, AIP Conf. Proc. 1728 (2016), 020373.

[16] G.V. Muddapur, R.M. Melavanki, P.G. Patil, D. Nagaraja, N.R. Patil, J. Mol. Liq. 224 (2016) 201-210.

[17] V.V. Koppal, G.V. Muddapur, N.R. Patil, R.M. Melavanki, AIP Conf. Proc. 1728 (2016), 020411.

[18] V.R. Desai, A.H. Sidarai, S.M. Hunagund, M. Basanagouda, R.M. Melavanki, R. H. Fattepur, J.S. Kadadevarmath, J. Mol. Liq. 223 (2016) 141-149.

[19] V.V. Koppal, G.V. Muddapur, N.R. Patil, R.M. Melavanki, AIP Conf. Proc. 1728 (2016), 020411.

[20] Kalpana Sharma, Raveendra Melavanki, S.S. Patil, R.A. Kusanur, N.R. Patil, V. M. Shelar, J. Mol.Struct. 1181 (2019) 474-487.

[21] Elena Kirilova, Artur Yanichev, Aleksandrs Puckins, Mendel Fleisher, Sergey Belyakov, Luminescence (2018) 1-9.

[22] H.S. Geethanjali, D. Nagaraja, R.M. Melavanki, J. Fluoresc. 25 (3) (2015) 745-753.

[23] N.R. Patil, R.M. Melavanki, S.B. Kapatkar, N.H. Ayachit, J. Saravanan, J. Flurosec. 21 (2011) 1213-1222.

[24] R.M. Melavanki, H.D. Patil, S. Umapathy, J.S. Kadadevarmath, J. Fluoresc. 22 (2012) 137-144.

[25] J.S. Kadadevarmath, G.H. Malimath, N.R. Patil, H.S. Geethanjali, R.M. Melavanki, Can. J. Phys. 91 (2013) 1107-1113.
[26] P.G. Patil, V.V. Koppal, R.M. Melavanki, N.R. Patil, Mater. Today Proc. 5 (2018) 2781-2786.

[27] P. Bhavya, Raveendra Melavanki, M.N. Manjunatha, V.V. Koppal, N.R. Patiland, V. T. Muttannavar, AIP Conf. Proc. (1953), 080022-1-080022-080025.

[28] V.V. Koppal, P.G. Patil, R.M. Melavanki, N.R. Patil, Mater. Today Proc. 5 (2018) 2759-2764.

[29] P. Bhavya, Raveendra Melavanki, Kalpana Sharma, R. Kusanur, N.R. Patil, J. Thipperudrappa, Chem. Data Collect. 19 (2019), 100182.

[30] Nejla Khatir-Hamdi, Malika Makhloufi-Chebli, Hocine Grib, M. éziane Brahimi, Artur M.S. Silva, J. Mol. Struct. 1175 (2019) 811-820.

[31] Yadigar Gulseven Sidır, Isa Sidır, Spectrochim. Acta Part A 102 (2013) 286-296.

[32] M.S. Zakerhamidi, S. Ahmadi-Kandjani, M. Moghadam, E. Ortyl, S. Kucharski, J. Mol. Struct. 996 (2011) 95-100.

[33] Ghanadzadeh Gilani, S.E. Hosseini, M. Moghadam, E. Alizadeh, Spectrochim. Acta Part A 89 (2012) 231-237.

[34] Gaddam Ramesh, Byru Venkatram Reddy, J. Mol. Struct. 1160 (15) (2018) 271-292.

[35] Mostafa Khajehzadeh, Nasrin Sad, J. Mol.Liq. 249 (2018) 281-293.

[36] Nuha A. Wazzan, Ohoud S. Al-Qurashi, H.M. Faidallah, J. Mol. Liq. 223 (2016) 29-47.

[37] R. Srivastava, F.M. Al-Omary, Ali A. El-Emam, S.K. Pathak, M. Karabacak, Vijay Narayan, Satish Ch, Onkar Prasad, Leena Sinha, J. Mol. Struct. 1137 (5) (2017) 725-741.

[38] Khairia M. Al-Ahmary, Ramadan Ahmed Mekheimer, Maha S. Al-Enezi, Nagwa M. M. Hamada, Moustafa M. Habeeb, J. Mol. Liq. 249 (2018) 501-510.

[39] Dhanraj R. Mohbiya, Nagaiyan Sekar, Chem. Select. 3 (2018) 1635-1644.

[40] Hasan Tanak, Ays En Agar, Metinyavuz, Int. J. Quant. Chem. 111 (2011) 2123-2136.

[41] S. Premkumar, A. Jawahar, T. Mathavan, M. Kumara Dhas, A. Milton Franklin Benial, Spectrochim. Acta Part A. 138 (2015) 252-263.

[42] S. Premkumar, A. Jawahar, T. Mathavan, M. Kumara Dhas, V.G. Sathe, A. Milton Franklin Benial, Spectrochim. Acta Part A 129 (2014) 74-83.

[43] S. Premkumar, T.N. RekhaBeulah, J.M. Rajkumar, R. Mohamed Asath, A. Jawahar, T. Mathavan, A. Milton Franklin Benial, Braz. J. Phys. 45 (6) (2015) 621-632.

[44] S. Premkumar, T.N. Rekha, R. Mohamed Asath, T. Mathavan, A. Milton Franklin Benial, Euro. J. Pharma. Sc. 82 (2016) 115-125.

[45] S. Premkumar, T.N. Rekha, R. Mohamed Asath, A. Jawahar, T. Mathavan, A. Milton Franklin Benial, J. Mol. Struct. 1107 (2016) 254-265.

[46] V.T. Muttannavar, R. Melavanki, P. Bhavya, R. Kusanur, N.R. Patil, L.R. Naik, Int. J. Life Sci. Phar. Res. 8 (3) (2018) 24-30.

[47] M.J. Frisch, G.W. Trucks, H.B. Schlegel, G.E. Scuseria, M.A. Robb, J.R. Cheeseman, G. Scalmani, V. Barone, B. Mennucci, G.A. Petersson, et al., Gaussian 09 RA. 1, Gaussian. Inc., Wallingford CT, 2009.

[48] A. Frisch, A.B. Nielsen, A.J. Holder, Gaussview User Manual, Gaussian Inc., Pittsburgh, PA, 2000, p. 556.

[49] R. Dengton, T. Keith, J. Millam, K. Eppinnett, W.L. Hovell, R. Gilliland, GaussView, Version 309, Semichem, Inc, Shawnee Mission, KS, 2003.

[50] E.D. Glendening, A.E. Reed, J.E. Carpenter, F. Weinhold, NBO Version 3.1, TCI. University of Wisconsin, Madison, 1998, p. 65.

[51] C. Wohlfarth, Static Dielectric Constants of Pure Liquids and Binary Liquid Mixtures: Supplement to IV/6, Springer Science \& Business Media, 2008.

[52] P. Suppan, C. Tsiamis, Spectrochim. ActaPartA 36 (1980) 971-974. Suppan, J. Chem. Soc. A 3125 (1968).

[53] C. Reichardt, Chem. Rev. 94 (1994) 2319-2358.

[54] M. Ravi, T. Soujnya, A. Samanta, T.P. Radhakrishnan, J. Chem. Soc. Faraday Trans. 91 (1995) 2739-2742.

[55] S. Premkumar, T.N. Rekha, R. Mohamed Asath, T. Mathavan, A. Milton Franklin Benial, Eur. J. Pharm. Sci. 82 (2016) 115-125.

[56] S. Premkumar, T.N. Rekha, R. Mohamed Asath, A. Jawahar, T. Mathavan, A. Milton Franklin Benial, J. Mol. Struct. 1107 (2016) 254-265.

[57] Zeynep Demircioğlu, Çiğdem Albayrak Kaștaș, Orhan Büyükgüngör, Spectrochim. Acta A. Mol. Biomol. Spectrosc. 15 (3) (2015) 539-548.

[58] Edina H. Avdović, Dejan Milenković, Jasmina M.Dimitrić Marković, Jelena Đorović, Nenad Vuković, Milena D. Vukić, Verica V. Jevtić, Srećko R. Trifunović, Ivan Potočñák, Zoran Marković, Spectrochim. Acta A Mol. Biomol. Spectrosc. 195 (4) (2018) 31-40.

[59] R.G. Parr, W. Yang, Density functional approach to the frontier-electron theory of chemical reactivity, J. Am. Chem. Soc. 106 (1984) 4049-4050.

[60] K. Fukui, Theory of Orientation and Stereoselection, Springer-Verlag, Berlin, 1975.

[61] L.I.U. Shu-BIN, Conceptual density functional theory and some recent developments, Acta Phys. ChimSin. 25 (2009) 590-600.

[62] http://www.molinspiration.com/cgi-bin/properties.

[63] R.A. Kusanur, M.V. Kulkarni, Asian J. Chem. 26 (4) (2014) 1077.

[64] R. Kalirajan, M. Pandiselvi, S. Sankar, B. Gowramma, S F J. Pharma. Anal. Chem. (2018). Science Forecast Publications LLC., | https://scienceforecastoa.com/ 2018 Volume 1 Edition 1 Article 1004.

[65] Dayanand Patagar, Raviraj Kusanur, Nikum D. Sitwala, Manjunath D. Ghate, Shanmugasundar Saravanakumar, Sharanappa Nembenna, Piyush A. Gediya, J. Heterocycl. Chem. 56 (10) (2019) 2761-2771.

[66] Amal Al Sabahi, Saleh N. Al Busafi, Fakhr Eldin O. Suliman, Salma M. Al Kindy, J. Mol. Liq. 307 (1) (2020), 112967. 